San Jose State University

SJSU ScholarWorks

Master's Theses

Master's Theses and Graduate Research

1997

\title{
Sleep hygiene practices and knowledge in different groups of college students
}

Kristy Lucero-Gorman

San Jose State University

Follow this and additional works at: https://scholarworks.sjsu.edu/etd_theses

\section{Recommended Citation}

Lucero-Gorman, Kristy, "Sleep hygiene practices and knowledge in different groups of college students" (1997). Master's Theses. 1512.

DOI: https://doi.org/10.31979/etd.3p9e-m8u5

https://scholarworks.sjsu.edu/etd_theses/1512

This Thesis is brought to you for free and open access by the Master's Theses and Graduate Research at SJSU ScholarWorks. It has been accepted for inclusion in Master's Theses by an authorized administrator of SJSU ScholarWorks. For more information, please contact scholarworks@sjsu.edu. 


\section{INFORMATION TO USERS}

This manuscript has been reproduced from the microfilm master. UMI films the text directly from the original or copy submitted. Thus, some thesis and dissertation copies are in typewriter face, while others may be from any type of computer printer.

The quality of this reproduction is dependent upon the quality of the copy submitted. Broken or indistinct print, colored or poor quality illustrations and photographs, print bleedthrough, substandard margins, and improper alignment can adversely affect reproduction.

In the unlikely event that the author did not send UMI a complete manuscript and there are missing pages, these will be noted. Also, if unauthorized copyright material had to be removed, a note will indicate the deletion.

Oversize materials (e.g., maps, drawings, charts) are reproduced by sectioning the original, beginning at the upper left-hand corner and continuing from left to right in equal sections with small overlaps. Each original is also photographed in one exposure and is included in reduced form at the back of the book.

Photographs included in the original manuscript have been reproduced xerographically in this copy. Higher quality 6" $\times 9$ " black and white photographic prints are available for any photographs or illustrations appearing in this copy for an additional charge. Contact UMI directly to order.

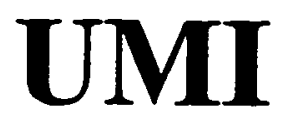

A Bell \& Howell Information Company 



\title{
SLEEP HYGIENE PRACTICES AND KNOWLEDGE IN DIFFERENT GROUPS OF COLLEGE STUDENTS
}

\author{
A Thesis \\ Presented to \\ the Faculty of the Department of Psychology \\ San Jose State University \\ In Partial Fulfillment \\ of the Requirements for the Degree \\ Master of Arts
}

by

Kristy Lucero-Gorman

August, 1997 
UMI Number: 1386213

Copyright 1997 by

Lucero-Gorman, Kristy Ellen

All rights reserved.

UMI Microform 1386213

Copyright 1997, by UMI Company. All rights reserved.

This microform edition is protected against unauthorized copying under Title 17, United States Code.

\author{
UMI \\ 300 North Zeeb Road \\ Ann Arbor, MI 48103
}


(C) 1997

Kristy Lucero-Gorman

ALL RIGHTS RESERVED 

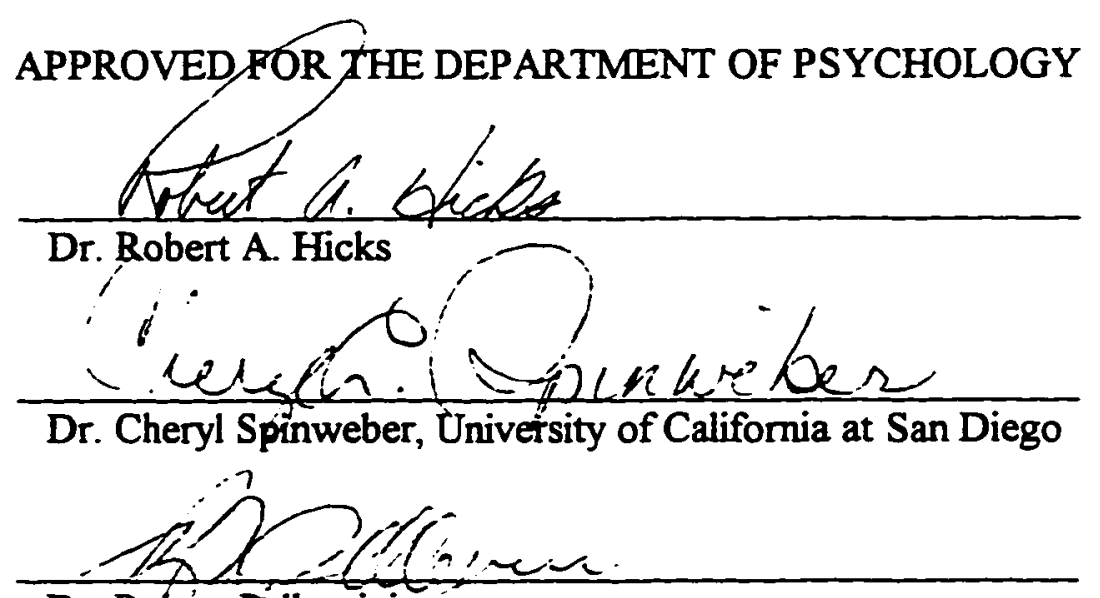

Dr. Robert Pellegrini

\section{APPROVED FOR THE UNIVERSITY}

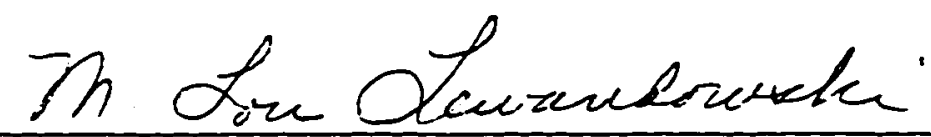




\title{
ABSTRACT \\ SLEEP HYGIENE PRACTICES AND KNOWLEDGE IN DIFFERENT GROUPS OF COLLEGE STUDENTS
}

\author{
by Kristy Lucero-Gorman
}

Recent reports have shown striking changes in the sleep habits, problems, and satisfaction with sleep among college students. However, there is, as yet, no research that has been focused on sampling the sleep habits, sleep problems, and the sleep-related knowledge of a large group of young adults that considers ethnicity and gender as variables. The purpose of this research was to provide a first study of this type.

A sample of 1100 students enrolled in introductory psychology classes from several Western Universities were asked to complete a questionnaire composed of the items from several established measures of sleep related habits, problems and knowledge. Subjects' data were divided into four different ethnic groups for purpose of analysis; these were African-American, Asian, Caucasian and Hispanic.

The clear conclusion is that both ethnicity and gender are related to several parameters of sleep. 


\section{ACKNOWLEDGMENTS}

I would like to thank my chairperson and mentor, Dr. Hicks for all his support, guidance and patience. I also wish to thank my family for all of their support, love and help in getting me through this. Additional thanks goes to Dr. Gray-Shellberg for all her help in gathering data. 


\section{TABLE OF CONTENTS}

SECTION

PAGE

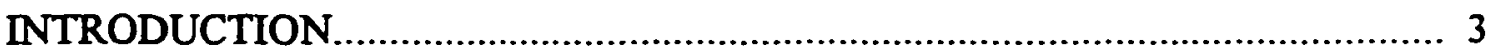

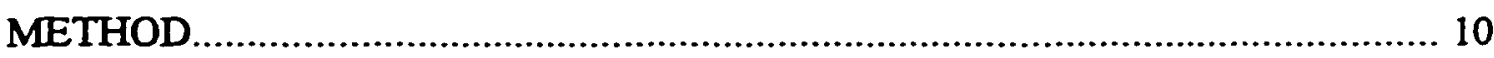

Research Participants....................................................................... 10

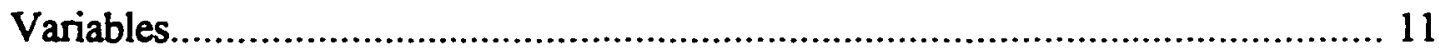

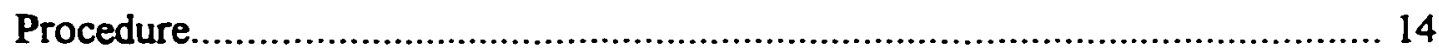

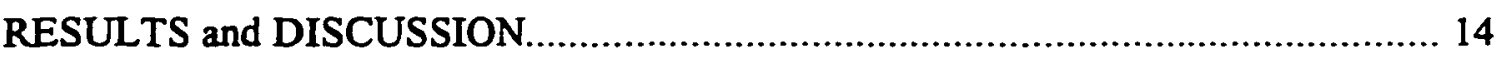

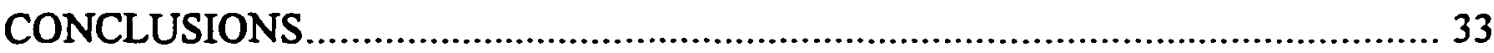

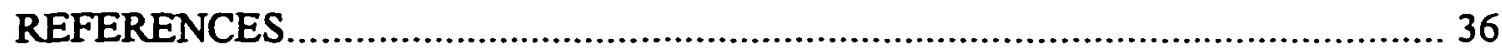

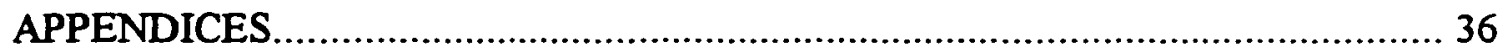

Appendix A. Owl and Lark Questionnaire ............................................... 39

Appendix B. Sleep Habits Questionnaire............................................. 43

Appendix C. Epworth Sleepiness Scale ................................................ 46

Appendix D. Stanford Sleepiness Scale............................................... 47

Appendix E. Coren's Insomnia Scale .................................................. 48

Appendix F. Pittsburgh Sleep Quality Index.......................................... 49

Appendix G. Sleep Hygiene Questionnaire......................................... 53

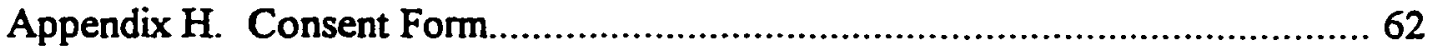




\section{LIST OF TABLES}

TABLE

PAGE

1. The Frequency of Self-Report Sleep Problems Among Type A and Type B College Students Derived From Samples Tested in 1982 and 1992 ........... 4

2. Percentages of Total Number of SJSU Students for Each Major Ethnic Group for Fall 1981 - Fall 1991.

3. The Frequency of Self-Reported Level of Snoring for Men From Four Countries.

4. The Number of Students in Each Major Ethnic Group and Gender 11

5. Means and Standard Deviations of Sleep Habits for Ethnicity and Gender. 15

6. The Frequency of Self-Reported Sleep Habits for Ethnicity and Gender 16

7. Means and Standard Deviations of Dream Measures for Ethnicity and Gender.

8. Means and Standard Deviations of Dream Types for Ethnicity and Gender 20

9. Means and Standard Deviations of Sleep Problems for Ethnicity and Gender.

10. Means and Standard Deviations of More Sleep Problems for Ethnicity and Gender.

11. The Frequency of Self-Reported Sleep Problems for Ethnicity and Gender. 28

12. Means and Standard Deviations of Sleep Knowledge and Hygiene Measures for Ethnicity and Gender 
Sleep Hygiene Practices and Knowledge in

Different Groups of College Students

Kristy Lucero-Gorman

San Jose State University

Running head: SLEEP, ETHNICITY AND GENDER

Footnotes

Requests for reprints should be sent to Kristy Lucero-Gorman, Department of Psychology, San Jose State University, San Jose, California 95192. 


\begin{abstract}
Recent reports have shown striking changes in the sleep habits, problems, and satisfaction with sleep among college students. However, there is, as yet, no research that has been focused on sampling the sleep habits, sleep problems, and the sleep-related knowledge of a large group of young adults that considers ethnicity and gender as variables. The purpose of this research was to provide a first study of this type. A sample of 1100 students enrolled in introductory psychology classes from several Western Universities were asked to complete a questionnaire composed of the items from several established measures of sleep related habits, problems and knowledge. Subjects' data were divided into four different ethnic groups for purpose of analysis; these were African-American, Asian, Caucasian and Hispanic. The clear conclusion is that both ethnicity and gender are related to several parameters of sleep.
\end{abstract}


Sleep Hygiene Practices and Knowledge in Different Groups of College Students

Recently, Hicks and Pellegrini (1991) reported that the median nightly sleep duration of college students had dropped from 7.75 hours in 1969 to 6.75 hours in 1989, i.e., a one hour reduction in sleep per night over a span of two decades. In a correlated study, earlier, we had reported (Hicks, Mistry, Lucero, Lee \& Pellegrini, 1989) that the percentages of students who reported sleep problems had risen from $24.4 \%$ in 1978 to $53.3 \%$ in 1988 , i.e., the incidence of self-reported sleep problems had doubled in college students over the period of one decade. Collectively, these changes in the quantity and the quality of the sleep of college students are striking and suggest a clear need for research designed to elaborate the variables that may be associated with these dramatic shifts in sleep. In this regard, recently completed studies by members of the San Jose State University sleep research group have offered some guidance in structuring the research to be proposed in this document and these are described in the following paragraphs.

\section{Sleep Quality and Stress Linked Personality Traits}

Perhaps the set of traits that have been most frequently linked to sleep quantity and quality of sleep are the behaviors that define the Type A-B syndrome. Here, it has been demonstrated that college students who are classified as Type $\mathbf{A}$ tend to sleep less than their Type B peers (e.g., see Hicks, Pellegrini, Martin, Garbesi, Elliot \& Hawkins, 1979). Of potentially greater significance for the research to be proposed here are the results of an earlier study by Hicks and Pellegrini (1982). On the assumptions that Type A people are simultaneously more active, and thus more likely to encounter stressful events (see Margiotta, Davilla \& Hicks, 1990, for confirming evidence of this), chronically more aroused (e.g., see Glass, 1977) and less able to cope with these stressful events (e.g., see Friedman \& Rosenman, 1977), than their Type B peers, they predicted that relative to 
Type B students, Type A students would be more likely to report sleep problems. As can be computed from their data, which are included in Table 1, the Type A students in this study were 2.51 times more likely to report sleep problems than the Type B students.

Table 1

The Frequency of Self-Report Sleep Problems Among Type A and Type B College Students Derived From Samples Tested in 1982 and 1992

\begin{tabular}{lccccc}
\hline & \multicolumn{2}{c}{1982} & & \multicolumn{2}{c}{$\underline{1992}$} \\
Group & No Problems & Problems & No Problems & Problems \\
\hline Type A (f) & 223 & $113(57 \%)$ & 134 & $290(56 \%)$ \\
Type B (f) & $21 \underline{1}$ & $45(43 \%)$ & 105 & $224(44 \%)$ \\
& $\chi^{2}(1, \underline{N}=592)=19.13, \underline{p}<.001$, & $\chi^{2}(1, \underline{N}=753)=.01, \underline{p}>.90$, \\
\multicolumn{2}{c}{ and $\phi^{\prime}=.180$} & and $\phi^{\prime}=.003$ \\
\hline
\end{tabular}

These data suggested that the increase in sleep problems reported by Hicks, Mistry, Lucero, Lee \& Pellegrini (1989) might be, in part, an increase in Type A-related behavior patterns among college students. Recently members of our sleep group (Hicks, Conti \& Pellegrini, 1992) tested for this possibility by replicating the Hicks and Pellegrini (1982) study. The results of this effort are also summarized in Table 1 . As can be seen by inspecting this Table, the proportion of Type A to Type B students in each sample is nearly identical and that for the 1992 sample, the distributions of Type A and Type B students who reported sleep problems or who did not report sleep problems were also nearly identical. As Hicks, Conti and Pellegrini state the most noteworthy change over the decade covered by the data listed in Table 1 , is the over-all increase in the number of 
students reporting sleep problems, i.e., from $26.7 \%$ in 1982 to $68.3 \%$ in 1992 . As they note, this change is significant with $\chi^{2}(1)=229.11, \mathrm{p}<.001$, and $\phi^{\prime}=.413$. Thus, these recently collected data provide evidence that since the publication of our earlier paper (Hicks et al., 1989), the incidence of sleep problems among college students has continued to rise and the possible reasons for this alarming change seem less clear.

Recently a Czechoslovakian scientist provided information in a letter (Sarmany, personal communication, 1992) related to the sleep habits of college students in his country that caused us to think differently about the factors that may have contributed to the changes in sleep that we have reported for students at San Jose State University. Specifically, Sarmany, noted that in attempting to replicate an earlier study done here, by members of the SJSU sleep group, (i.e., Hicks, Lucero \& Mistry, 1991), that found a difference in the frequency of nightmares reported by habitual short- ( $\leq 6$ hours/night) and longer-sleepers ( $\geq 8$ hours/night), that he was unable to complete the study because he could not find a sufficient number of short-sleeping students at his Czechoslovakian university. His inability to find sufficient short-sleepers is exactly 180 degrees out of phase with the problems we experienced in completing a study designed to measure differences in eating and the nature of the diets of short- and longer-sleeping college students (Lucero \& Hicks, 1990; Lucero, Hicks, Mistry \& Bautista, 1991). In this research project, which we felt could be completed in about one semester, we encountered unanticipated difficulties in identifying a sample of longer sleepers and as a consequence it took three semesters to complete this study. In fact, it was this difficulty that led us to wonder if the sleep habits of college students had changed and the impetus for three subsequent studies (Hicks et al., 1989; Hicks, Mistry, Lucero, Marical \& Pellegrini, 1990; Hicks \& Pellegrini, 1991) that documented the changes in sleep quantity and quality that I have noted in the forgoing paragraphs. 


\section{Ethnicity, Culture and Sleep}

Collectively, the observations in the preceding section of this proposal, suggest that perhaps the changes that we have reported for students at San Jose State University are, at least in part, a function of systematic changes in the student population of this university over the 15-year period that has elapsed since the initial observations were made.

A significant change that has occurred in the demographic make-up of our students during this period, is the continuous increase in the ethnic diversity of the SJSU student body. As close as available statistics permit, these changes are summarized in Table 2 for the most recent available decade.

Table 2

Percentages of Total Number of SJSU Students for Each Major Ethnic Group for Fall 1981 - Fall 1991

\begin{tabular}{lrrrrrrrrrrr}
\hline Group & 1981 & 1982 & 1983 & 1984 & 1985 & 1986 & 1987 & 1988 & 1989 & 1990 & 1991 \\
\hline Asian & 9.8 & 12.1 & 13.6 & 14.5 & 15.8 & 17.4 & 18.5 & 19.3 & 20.5 & 21.3 & 22.6 \\
Black & 4.5 & 4.4 & 4.7 & 4.6 & 4.2 & 4.0 & 3.9 & 3.9 & 3.9 & 3.9 & 4.0 \\
Filipino & 1.7 & 2.0 & 2.3 & 2.5 & 2.7 & 3.0 & 3.2 & 3.5 & 3.8 & 4.1 & 4.2 \\
Hispanic & 6.1 & 6.8 & 7.0 & 7.0 & 7.1 & 7.1 & 7.7 & 8.4 & 8.3 & 8.8 & 9.0 \\
White & 47.4 & 54.3 & 57.9 & 56.9 & 58.8 & 58.9 & 58.0 & 56.4 & 54.4 & 52.0 & 49.8 \\
Other & 30.5 & 20.6 & 14.4 & 14.5 & 11.4 & 9.6 & 8.7 & 8.6 & 9.1 & 9.8 & 10.3 \\
\hline
\end{tabular}

The changes in patterns of ethnic diversity that have occurred on our campus that are summarized in Table 2 seem at least superficially to be correlated with the changes in sleep quantity and quality that have been documented among our students over this period of 
time. Further, while the related literature is sparse and indirect, it suggests that ethnicity and/or acculturation may be factors which contribute systematically to variance in sleep habits and the incidence of sleep disorders. In this regard, Domino and his colleagues (Domino, Romero, Blair, Villalobos, Suriano \& Bridges, 1985) administered a sleep questionnaire to 850 adults (age 50 and older) drawn from urban areas in seven countries, i.e., Australia, Greece, Italy, Mexico, Spain, Venezuela, and the United States. All his respondents were healthy, functioning adults and their samples were equated for age, gender and occupational level. They computed significant main effects for countries on six of their sleep variables, i.e., depth of sleep, difficulty in waking up, negative dream affect, length of sleep, dream recall and sleep irregularity and two significant main effects for gender, i.e., women reported lighter sleep and longer latency to sleep onset than men. There were no significant countries by gender interactions. In a subsequent study, Domino (1986) studied the sleep habits of Hispanic adults drawn from Mexico, Spain, Venezuela and the United States. All of these subjects were 50 years and older, natives of their culture and healthy urban residents. These samples were roughly equivalent with respect to gender, age, occupational level and employment status. Significant main effects for countries were computed for five of the seven sleep variables, i.e., difficulty in waking up, negative dream affect, length of sleep, dream recall and sleep irregularity. As was the case in this group's earlier study, women reported significantly lighter sleep and longer latency to sleep onset. There were no significant countries by gender interactions. Thus, given their limitations, these studies by Domino and his colleagues suggest that both culture and gender are variables that may contribute to differences in the quantity and quality of sleep between groups of people.

In addition to these studies, there is some evidence that can be adduced from the literature that suggests the importance of culture and/or ethnicity in a sleep problem, i.e., 
snoring, While snoring is most likely to be viewed as a problem by persons who sleep with an individual who snores, it is considered as a potential sleep problem for the snorer by sleep disorders experts because it may be a sign of sleep apnea, i.e., the most serious of all of the sleep disorders that have been identified to date.

The causes of snoring are not known and recently in an attempt to elaborate these, Perez-Padilla (1991) argued that genetic differences (e.g., structure of the palate), gender (snoring is more common in men) and age (snoring tends to become more frequent as a function of aging) are the primary determinants of snoring. In making this argument he mentioned without comment, that "Various authors estimate the prevalence of snoring, habitual and occasional, in the adult population to $16-89 \% "$ (p. 37). The range provided by these estimates of the prevalence of snoring is striking and upon investigation, they suggested to us the possibility that Perez-Padilla had over-looked an obvious additional factor that might be associated with the prevalence of snoring, i.e., culture. To explain, each of the studies that had estimated the prevalence of snoring that Perez-Padilla cited (and some that he did not cite) were all carried out in different countries using different cultural groups. Recently, Hicks, Bautista, and McCullough (1994) compared data from the four epidemiological studies that had measured the frequency of self-reports of snoring of adult males (Lugaresi, Cirignotta, Coccagna \& Piana, 1980; Koskenvuo, Kaprio, Telakivi, Partinen, Heikkila \& Sarna, 1987; Gislason, Aberg \& Taube, 1987; Hicks \& McCullough, 1992). Before proceeding, it should be noted that only males were used in this analysis because two of these studies (Koskenvuo et al. and Gislason et al.) did not seek responses from women. Further, only one of these studies provides sufficient information to measure differences in the prevalence of snoring as a function of age (Koskenvuo et al.) and only one of these studies provided sufficient data to measure differences in prevalence of snoring as a function of gender (Hicks and McCullough). 
As was mentioned, these samples were drawn from four different countries; the Republic of San Marino (Lugaresi et al., 1980), Finland (Koskenvuo et al., 1987), Sweden (Gislason et al., 1987), and the United States (Hicks \& McCullough, 1992). The data derived from each sample are organized in Table 3.

Table 3

The Frequency of Self-Reported Level of Snoring for Men From Four Countries

\begin{tabular}{lrrrr}
$\begin{array}{l}\text { Origin of } \\
\text { the Sample }\end{array}$ & Habitual & Occasional & Never & Total \\
\hline San Marino & $688(24 \%)$ & $480(17 \%)$ & $1688(59 \%)$ & 2856 \\
Finland & $1294(29 \%)$ & $2614(60 \%)$ & $480(11 \%)$ & 4388 \\
Sweden & $487(23 \%)$ & $928(43 \%)$ & $719(34 \%)$ & 2134 \\
United States & $26(7 \%)$ & $179(50 \%)$ & $151(42 \%)$ & 356 \\
\hline
\end{tabular}

The difference in the snoring level distributions summarized in Table 3 are significant: $\chi^{2}(6)=2127.29, p<.001$ with $\phi^{\prime}=.331$. Further, when the snoring level distributions for age that were analyzed, the difference between these was significant: $\chi^{2}(4)=25.61$, $\mathrm{p}<.001$ with $\phi^{\prime}=.054$. Finally, the difference in the distribution of level of snoring for United States men and women that Hicks and McCullough (1992) reported were also significant: $\chi^{2}(4)=23.70, \mathrm{~g}<.001$ with $\phi^{\prime}=.178$. Thus, by examination of the Phi statistics computed from these distributions, it appears that the culture from which the sample is drawn is a more salient factor in the level of snoring than either age or gender. 


\section{The Problem and the Purpose of this Research}

The discussion provided in the forgoing paragraphs indicate that sleep habits have changed among college students on this campus in a manner that has dramatically increased the frequency of sleep problems. The factors that have led to these changes are unknown but systematic changes in the ethnic diversity of our student population might be implicated. That is, while the relevant literature is sparse, it is consistent in suggesting that culture and/or ethnicity are variables that correlated with sleep quantity and quality. However, as the review of this literature has shown, there is, as yet, no research that has been focused on sampling the sleep habits, sleep problems, and the sleep-related knowledge of a large group of young adults, within a given geographic area, that considers ethnicity and gender as variables. The purpose of this research is to provide a first study of this type and it is hypothesized that there will be differences in sleep habits, sleep problems, and sleep-related knowledge between ethnic groups and between genders.

\section{Method}

\section{Participants}

Our initial sample consisted of 1969 urban dwelling college undergraduates enrolled in introductory psychology classes from San Jose State University, California State University Dominguez Hills and San Francisco State University. Since we were only interested in data from the following ethnic groups--African-American, Asian, Caucasian and Hispanic--our final sample was 1100, summarized in Table 4. 
Table 4

The Number of Students in Each Major Ethnic Group and Gender

\begin{tabular}{lccl}
\hline Group & Males $(\underline{N}=497)$ & Females $(\underline{N}=603)$ & Total $\underline{N}=1100)$ \\
\hline African-American & 45 & 62 & 107 \\
Asian & 213 & 241 & 454 \\
Caucasian & 150 & 162 & 312 \\
Hispanic & 89 & 138 & 227 \\
\hline
\end{tabular}

Ethnicity was determined by having subjects respond to the question "what is your ethnic or racial origin?" (See Appendix B, Question 19). Here it should be noted that it would have been desirable to sample the responses of Native American Indians but since numbers of students enrolled at the urban colleges that were utilized are low, sufficient numbers of these students were not available for this study.

\section{Variables}

In describing their scale, The Pittsburgh Sleep Quality Index, Buysse and his colleagues (Buysse, Reynolds, Monk, Berman \& Kupfer, 1989) stated that sleep quality "... represents a complex phenomenon that is difficult to define and measure objectively." (p. 194). This caution has been considered and taken into account in selecting the variables that were included in the questionnaire that has been developed for this study. Given the complexity and difficulty of obtaining reliable self-reports of sleep, it seemed prudent to include several established measures of sleep-related habits, problems and knowledge rather than rely on a single measure. Thus, the questionnaire that was used in this study was composed of the items from these scales; The Owl and Lark Questionnaire (Horne \& Ostberg, 1976), the Sleep Habits Questionnaire (Hicks, Mistry, Lucero, Lee 
\& Pellegrini, 1989), the Dream Types Questionnaire (Spadafora \& Hunt, 1990), the Epworth Sleepiness Scale (Johns, 1991), the Stanford Sleepiness Scale (Hoddes, Zarcone, Smythe, Phillips \& Dement, 1973), the Coren Insomnia Scale (Coren, 1988), and the Pittsburgh Sleep Quality Index (Buysse et al.). In addition to these scales, a set of items have been written that reflect an individuals general knowledge of sleep and sleep hygiene, it is called the Sleep Hygiene Questionnaire. In developing these items, special attention was paid to a book by Milter and Milter (1990) titled "101 Questions About Sleep and Dreams" and the Sleep Hygiene Awareness and Practice Scale (Lacks, 1987). In the following paragraphs each of these scales or set of items is described.

\section{Sleep Habits}

Owl and Lark Questionnaire (O\&L): This scale contains 19 self-reported questions about how subjects feel about doing certain things at certain times of the day, for example, "How is your appetite during the first half-hour after having woken in the mornings?". The scores are added together and the sum is converted into a 5-point morningnesseveningness scale ranging from $70-86$, definitely morning type to $16-30$, definitely evening type (See Appendix A).

Sleep Habits Questionnaire (SHQ): This 30 item self-report questionnaire is used to find out basic information about a person's sleep habits and dreams. It includes such items as how long one sleeps on an average night and if one dreamt last night (See Appendix B). Dreams

Dream Types Questionnaire (DTO): This 7 item self-report questionnaire is used to determine the frequency, ranging from always (or almost always) to never (or almost never), and the type of dreams the subjects have, e.g. lucid dreams, night terrors (See Question 20, Page 60, Appendix G). 


\section{Sleep Problems}

Epworth Sleepiness Scale (ESS): This self-report scale is designed to measure sleep propensity. Subjects are asked to rate how likely they would be to doze off or fall asleep in eight situations on a scale of 0 -would never doze to 3-high chance of dozing (See Appendix C).

Stanford Sleepiness Scale (SSS): This scale contains 7 statements that subjects use to rate their sleepiness at any given time of day or night. The scale ranges from 1-feeling active and vital; alert; wide awake to 7-almost in reverie; sleep onset soon; lost struggle to remain awake (See Appendix D).

Coren Insomnia Scale (CIS): This scale contains 11 self-reported questions which assess insomnia. A score of $\geq 33$ indicates a high incidence of insomnia and a score of $\leq 25$ indicates a low incidence of insomnia (See Appendix E).

Pittsburgh Sleep Quality Index (PSOI): This scale contains 19 self-reported questions which assess a variety of factors relating to sleep quality. It takes about 5 to 10 minutes to take and 5 minutes to score. It was scored and used in the same manner that Buysse et al. (1989) did in their study (See Appendix F).

\section{Sleep Knowledge and Hygiene}

Sleep Hygiene Questionnaire (SHyO): There are 65 items that are contained in the questionnaire about an individuals general knowledge of sleep and sleep hygiene. Sleep hygiene refers to sleep habits and practices conducive to good sleep (Hauri, 1977) and includes information on sleep scheduling, choice of activities occurring prior to sleep, and preparation of the sleep setting (Schoicket, Bertelson and Lacks, 1988). It contains the Sleep Hygiene Awareness and Practice Scale (SHAPS) (Lacks, 1987) to assess subjects sleep hygiene practices and it was used to assess their general knowledge of sleep (See Appendix G). 


\section{Procedure}

First, the study was explained to the participants. Then each person who agreed to participate was asked to read and sign a consent form authorizing the use of their questionnaire for the purposes of this study. A copy of the consent form is included in Appendix $\mathrm{H}$. The questionnaire was handed out to each subject and complete instructions on how to fill it out were given. This packet was collected on the same day as distributed. Then subjects data were divided into gender by ethnic groups for purpose of analyses of these data.

\section{Results and Discussion}

To test the overall differences in the previously mentioned variables across gender and ethnicity, separate 2 (gender) by 4 (ethnicity) analysis of variances as well as chi-squared analysis were computed. All of the statistical analysis were performed using the Statistical Package for Social Science (SPSS). For purpose of discussion the variables have been categorized into four areas, i.e., Sleep Habits, Dreams, Sleep Problems and Sleep Knowledge and Hygiene.

\section{Sleep Habits}

Table 5 presents the means and standard deviations for each ethnic by gender group for sleep habits measured by the Owl and Lark Questionnaire and the Sleep Habits Questionnaire. Separate analyses of the data for each measure are considered in the following paragraph. 
Table 5

Means and Standard Deviations of Sleep Habits for Ethnicity and Gender

\begin{tabular}{rcc}
\hline Owl and Lark & $\begin{array}{c}\text { Sleep } \\
\text { Length (Hrs) Naps (Month) }\end{array}$ & $\begin{array}{c}\text { Number of Lenth of Naps } \\
\text { (Min) }\end{array}$ \\
\hline
\end{tabular}

Ethnicity

\begin{tabular}{|c|c|c|c|c|c|}
\hline n- & $\begin{array}{l}\text { Males } \\
\text { Females } \\
\text { Total }\end{array}$ & $\begin{array}{l} \pm 7.80 \\
\pm 8.18 \\
\pm 8.00\end{array}$ & $\begin{array}{l}6.89 \pm 1.18 \\
6.98 \pm 1.38 \\
6.94 \pm 1.28\end{array}$ & $\begin{array}{l}14.79 \pm 10.33 \\
12.74 \pm 7.97 \\
13.77 \pm 9.15\end{array}$ & $.52 \pm 44.49$ \\
\hline $\begin{array}{l}\operatorname{sian} \\
=454\end{array}$ & & & & $\begin{array}{l}2 \pm 9.55 \\
7 \pm 10.91 \\
5 \pm 10.23\end{array}$ & \\
\hline sian & $\begin{array}{l}\text { Males } \\
\text { Females } \\
\text { Total }\end{array}$ & $\begin{array}{l}47.07 \pm 8.85 \\
47.96 \pm 7.68 \\
47.52 \pm 8.26\end{array}$ & $\begin{array}{l}7.10 \pm .98 \\
7.25 \pm .99 \\
7.18 \pm .99\end{array}$ & $\begin{array}{r}12.23 \pm 8.12 \\
9.93 \pm 7.29 \\
11.08 \pm 7.70\end{array}$ & \\
\hline & $\begin{array}{l}N \\
F\end{array}$ & $\begin{array}{l}48.26 \pm 7 \\
51.68 \pm 7 \\
49.97 \pm 7\end{array}$ & $\begin{array}{l} \pm .91 \\
\pm 1.13 \\
+1.02\end{array}$ & $\begin{array}{l} \pm 13 . \\
+10 .\end{array}$ & $\begin{array}{l}57.04 \pm 30.02 \\
56.02 \pm 35.29 \\
56.53 \pm 32.65\end{array}$ \\
\hline
\end{tabular}

The data for the Owl and Lark scale showed both a main effect for ethnicity $\underline{F}_{3}, 1061=5.17, \mathrm{p}=.002$ and gender $\underline{F}_{1,1061}=14.49, \mathrm{p}<.001$ but no gender by ethnicity interaction (i.e., $\underline{F}_{3}, 1061=1.59$ ). By inspecting Table 5 it can be seen that Hispanics and females displayed more morning type tendencies and African-Americans and males displayed more evening type tendencies. As was the case with the studies done by Domino et al. (1985) and Domino (1986) that found significant main effects for countries and length of sleep, the sleep length data in this study also showed a main effect for ethnicity $\underline{F}_{3}, 1091=6.52, \mathrm{D}<.001$ but the main effect for gender and the gender by ethnicity interaction was not significant (i.e. $\underline{F}_{1,1091}=0.45$ and $\underline{F}_{3}, 1091=0.39$, 
respectively). In examining the reason for the significant main effect for sleep length, as is shown in Table 5, Asians reported sleeping the least and Caucasians the most. Overall it is interesting to note that sleep quantity is still relatively low, 7.00 hours per night. The data for number of naps taken showed a main effect for gender $\underline{F}_{1,526}=5.35, \underline{p}=.02$, with men reporting taking more naps per month than women. The main effects for ethnicity and the gender by ethnicity interaction were not significant, i.e., $\underline{F}_{3}, 526=1.70$ and $\underline{F}_{3}, 526=0.45$, respectively. The data for length of naps showed no significant differences.

Table 6 is a set of contingency tables showing the frequency of yes-no responses by individuals in each ethnic group and gender to these questions: "Do you generally get all of the sleep that you need each night?", "Are you generally satisfied with your sleep each night?" and "Do you take naps during the day?".

Table 6

The Frequency of Self-Reported Sleep Habits for Ethnicity and Gender

\begin{tabular}{|c|c|c|c|c|c|c|}
\hline \multirow[t]{2}{*}{ Get } & \multicolumn{2}{|c|}{$\begin{array}{l}\text { Get All The Sleep You Need } \\
\qquad \underline{\mathbf{N}}=1096)\end{array}$} & \multicolumn{2}{|c|}{$\begin{array}{l}\text { Satisfied With Sleep } \\
\underline{\underline{N}}=1097)\end{array}$} & \multicolumn{2}{|c|}{$\begin{array}{l}\text { Take Naps } \\
\underline{N}=1095)\end{array}$} \\
\hline & Yes & No & Yes & No & Yes & No \\
\hline African-American & 28 & 79 & 38 & 69. & 58 & 48 \\
\hline Asian & 135 & 318 & 215 & 237 & 239 & 214 \\
\hline Caucasian & 127 & 183 & 155 & 156 & 167 & 143 \\
\hline Hispanic & 72 & 154 & 98 & 129 & 95 & 131 \\
\hline
\end{tabular}




\begin{tabular}{lccllll} 
& Get All The Sleep You Need & \multicolumn{2}{l}{ Satisfied With Sleep } & \multicolumn{2}{c}{ Take Naps } \\
& \multicolumn{2}{c}{$(\underline{N}=1095)$} & \multicolumn{2}{c}{$(\underline{N}=1096)$} & \multicolumn{2}{c}{$(\underline{N}=1094)$} \\
Group & Yes & No & Yes & No & Yes & No \\
\hline Male & 171 & 325 & 229 & 267 & 260 & 235 \\
Female & 191 & 408 & 276 & 324 & 298 & 301 \\
\hline
\end{tabular}

Data for getting all the sleep needed showed a significant difference in regards to ethnicity $\chi^{2}(3)=13.38, \mathrm{p}=.004$, and $\phi^{\prime}=.11$ but no significant difference in regards to gender (i.e., $\chi^{2}(1)=.822$ ). By inspecting Table 6, it can be seen that more Caucasian students felt they were getting all the sleep they needed while fewer African-American students felt that they were getting all the sleep that they needed. The data for being satisfied with ones sleep also showed a significant difference in regards to ethnicity $\chi^{2}(3)=7.75, p=.05$, and $\phi^{\prime}=.08$, with African-Americans being the least satisfied with their sleep and Caucasians being more satisfied with their sleep and again no significant difference in regards to gender (i.e., $\chi^{2}(1)=.0032$ ). Taking naps also showed a significant difference for ethnicity, $\chi^{2}(3)=9.44, p=.02$, and $\phi^{\prime}=.09$ but no significant difference for gender (i.e., $\chi^{2}(1)=.835$ ). Hispanics were the least likeiy to nap, $58 \%$ reported they did not and African-Americans napped the most, $55 \%$ reported that they did. Overall reported sleep quality is low, $68 \%$ of the students responded no to the question "Do you generally get all of the sleep that you need each night?" and 56\% responded no to the question "Are you generally satisfied with your sleep each night?". These findings support the studies done by Hicks, Mistry, Lucero, Lee \& Pellegrini (1989) and by Hicks, Conti and Pellegrini (1992) that reported a change in sleep quality and sleep problems of students. 


\section{Dreams}

Table 7 presents the means and standard deviations for each ethnic by gender group for the first set of dream measures. Separate analyses of the data for each question are considered in the following paragraph.

Table 7

Means and Standard Deviations of Dream Measures for Ethnicity and Gender

\begin{tabular}{cccc}
\hline $\begin{array}{c}\text { Number of } \\
\text { Dreams }\end{array}$ & $\begin{array}{c}\text { Dreams } \\
\text { Remembered }\end{array}$ & $\begin{array}{c}\text { Dreams Are } \\
\text { Valuable }\end{array}$ & $\begin{array}{c}\text { Pain While } \\
\text { Dreaming }\end{array}$ \\
\hline
\end{tabular}

Ethnicity

\begin{tabular}{llllll} 
African- & Males & $1.59 \pm 1.11$ & $3.35 \pm 1.17$ & $2.80 \pm 1.10$ & $1.64 \pm .88$ \\
American & Females & $1.87 \pm 1.10$ & $3.72 \pm 1.24$ & $2.98 \pm 1.06$ & $1.81 \pm .94$ \\
$\underline{N}=105$ & Total & $1.73 \pm 1.11$ & $3.53 \pm 1.20$ & $2.89 \pm 1.08$ & $1.73 \pm .91$ \\
& & & & & \\
& Males & $1.62 \pm 1.26$ & $3.29 \pm 1.01$ & $2.84 \pm 1.11$ & $1.95 \pm 1.00$ \\
Asian & Females & $1.58 \pm .96$ & $3.52 \pm 1.02$ & $2.99 \pm 1.13$ & $2.09 \pm 1.01$ \\
$\underline{N}=448$ & Total & $1.60 \pm 1.11$ & $3.41 \pm 1.02$ & $2.92 \pm 1.12$ & $2.02 \pm 1.01$ \\
& & & & & \\
& Males & $1.86 \pm 1.43$ & $3.37 \pm 1.02$ & $2.95 \pm 1.12$ & $1.66 \pm .75$ \\
Caucasian & Females & $1.92 \pm .95$ & $3.66 \pm 1.04$ & $3.02 \pm 1.06$ & $2.09 \pm 1.03$ \\
$\underline{N}=307$ & Total & $1.89 \pm 1.19$ & $3.52 \pm 1.03$ & $2.98 \pm 1.09$ & $1.88 \pm .89$ \\
& & & & & \\
& Males & $1.71 \pm 1.12$ & $3.55 \pm 1.12$ & $2.76 \pm 1.21$ & $1.73 \pm .97$ \\
Hispanic & Females & $1.89 \pm .97$ & $3.63 \pm 1.08$ & $3.04 \pm 1.05$ & $2.06 \pm 1.13$ \\
$\mathbf{N}=225$ & Total & $1.80 \pm 1.04$ & $3.59 \pm 1.10$ & $2.90 \pm 1.13$ & $1.89 \pm 1.05$ \\
\hline
\end{tabular}

Note. For all values, $1=$ never to $6=$ always.

Data for number of dreams each night showed a main effect for ethnicity $\underline{F}_{3}, 1073=$ $4.28, p=.005$ but the main effect for gender and the gender by ethnicity interaction were not significant (i.e., $\underline{F}_{1}, 1073=1.03$ and $\underline{F}_{3}, 1073=0.78$, respectively). By inspecting Table 7, it can be seen that Caucasians reported having the most dreams and Asians the 
least. Data for remembering dreams showed a main effect for gender $\underline{F}_{1,1070}=12.69$, $p<.001$ but the main effect for ethnicity and the gender by ethnicity interaction were not significant (i.e., $\underline{F}_{3}, 1070=1.68$ and $\underline{F}_{3}, 1070=0.62$, respectively) and the data for dreams are valuable also showed a main effect for gender $\underline{F}_{1,1070}=5.01, p=.03$ but again the main effect for ethnicity and the gender by ethnicity interaction were not significant, $\underline{F}_{3}, 1070=0.29$ and $\underline{F}_{3}, 1070=0.33$, respectively. Experiencing pain while dreaming showed a significant main effect for gender $\underline{E}_{1,1070}=20.02, p<.001$ but no main effect for ethnicity or gender by ethnicity interaction, $\underline{F}_{3}, 1070=2.20$ and $\underline{F}_{3}, 1070$ $=1.56$, respectively. By inspecting Table 7, it can be seen that women reported remembering their dreams more, having more valuable dreams and experiencing more pain while dreaming than men. This data is inconsistent with the Domino et al. (1985) and Domino (1986) studies that found a significant main effect for countries and dream recall, but no gender differences.

Table 8 presents the means and standard deviations for each ethnic by gender group for the seven dream types measured by the Spadafora and Hunt scale. Separate analyses of the data for each dream type are considered in the following paragraph. 
Table 8

Means and Standard Deviations of Dream Types for Ethnicity and Gender

\begin{tabular}{cccc}
\hline Archetypal & Night & Fantastic & Prelucid \\
Dreams & Terrors & Nightmares & Dreams \\
\hline
\end{tabular}

Ethnicity

\begin{tabular}{llllll} 
African- & Males & $2.21 \pm 1.20$ & $1.69 \pm .95$ & $1.90 \pm .85$ & $2.36 \pm 1.20$ \\
American & Females & $2.00 \pm 1.01$ & $1.79 \pm .92$ & $2.34 \pm 1.09$ & $2.31 \pm 1.07$ \\
$\mathbf{N}=105$ & Total & $2.10 \pm 1.10$ & $1.74 \pm .93$ & $2.12 \pm .97$ & $2.34 \pm 1.13$ \\
& & & & & \\
& Males & $2.30 \pm 1.01$ & $1.68 \pm .89$ & $2.20 \pm 1.03$ & $2.19 \pm .98$ \\
Asian & Females & $2.23 \pm 1.08$ & $1.70 \pm .92$ & $2.51 \pm 1.03$ & $2.32 \pm 1.05$ \\
$\mathbf{N}=448$ & Total & $2.26 \pm 1.05$ & $1.69 \pm .90$ & $2.35 \pm 1.03$ & $2.26 \pm 1.01$ \\
& & & & & \\
& Males & $2.11 \pm .94$ & $1.34 \pm .59$ & $1.97 \pm .86$ & $2.19 \pm .95$ \\
Caucasian & Females & $1.93 \pm .93$ & $1.50 \pm .85$ & $2.65 \pm 1.01$ & $2.59 \pm 1.06$ \\
$\mathbf{N}=307$ & Total & $2.02 \pm .93$ & $1.42 \pm .72$ & $2.31 \pm .93$ & $2.39 \pm 1.01$ \\
& & & & & \\
& Males & $2.15 \pm 1.02$ & $1.46 \pm .82$ & $2.07 \pm 1.08$ & $2.36 \pm 1.06$ \\
Hispanic & Females & $2.01 \pm 1.15$ & $1.71 \pm 1.07$ & $2.56 \pm 1.20$ & $2.39 \pm 1.08$ \\
$\mathbf{N}=225$ & Total & $2.08 \pm 1.09$ & $1.58 \pm .94$ & $2.31 \pm 1.14$ & $2.38 \pm 1.07$ \\
\hline
\end{tabular}

Note. For all values, $1=$ never to $6=$ always. 


\begin{tabular}{|c|c|c|c|c|}
\hline & & $\begin{array}{c}\text { Post Traumatic } \\
\text { Nightmares }\end{array}$ & $\begin{array}{l}\text { Lucid } \\
\text { Dreams }\end{array}$ & $\begin{array}{l}\text { Control } \\
\text { Dreams }\end{array}$ \\
\hline \multicolumn{5}{|l|}{ Ethnicity } \\
\hline $\begin{array}{l}\text { African- } \\
\text { American } \\
\underline{N}=105\end{array}$ & $\begin{array}{l}\text { Males } \\
\text { Females } \\
\text { Total }\end{array}$ & $\begin{array}{l}1.77 \pm .96 \\
1.87 \pm 1.00 \\
1.82 \pm .98\end{array}$ & $\begin{array}{l}2.77 \pm 1.22 \\
2.82 \pm 1.31 \\
2.80 \pm 1.27\end{array}$ & $\begin{array}{l}2.23 \pm 1.14 \\
2.29 \pm 1.14 \\
2.26 \pm 1.14\end{array}$ \\
\hline $\begin{array}{l}\text { Asian } \\
\underline{N}=448\end{array}$ & $\begin{array}{l}\text { Males } \\
\text { Females } \\
\text { Total }\end{array}$ & $\begin{array}{l}1.85 \pm 1.00 \\
1.94 \pm 1.07 \\
1.89 \pm 1.03\end{array}$ & $\begin{array}{l}2.52 \pm 1.18 \\
2.64 \pm 1.13 \\
2.58 \pm 1.15\end{array}$ & $\begin{array}{l}2.24 \pm .98 \\
2.17 \pm 1.07 \\
2.21 \pm 1.02\end{array}$ \\
\hline $\begin{array}{l}\text { Caucasian } \\
\underline{\underline{N}}=307\end{array}$ & $\begin{array}{l}\text { Males } \\
\text { Females } \\
\text { Total }\end{array}$ & $\begin{array}{l}1.64 \pm .90 \\
2.02 \pm 1.18 \\
1.83 \pm 1.04\end{array}$ & $\begin{array}{l}2.53 \pm 1.03 \\
2.79 \pm 1.07 \\
2.66 \pm 1.05\end{array}$ & $\begin{array}{l}2.31 \pm 1.01 \\
2.30 \pm .99 \\
2.30 \pm 1.00\end{array}$ \\
\hline $\begin{array}{l}\text { Hispanic } \\
\mathrm{N}=225\end{array}$ & $\begin{array}{l}\text { Males } \\
\text { Females } \\
\text { Total }\end{array}$ & $\begin{array}{l}1.73 \pm .92 \\
1.94 \pm 1.10 \\
1.83 \pm 1.01\end{array}$ & $\begin{array}{l}2.74 \pm 1.23 \\
2.65 \pm 1.24 \\
2.70 \pm 1.23\end{array}$ & $\begin{array}{l}2.32 \pm 1.12 \\
2.33 \pm 1.03 \\
2.32 \pm 1.08 \\
\end{array}$ \\
\hline
\end{tabular}

Note. For all values, $1=$ never to $6=$ always.

Data for Archetypal Dreams showed both a main effect for ethnicity $\underline{F}_{3}, 1060=3.66$, $\mathrm{p}=.01$ and gender $\underline{F}_{1}, 1060=4.23, \mathrm{p}=.04$ and but the gender by ethnicity interaction was not significant $\underline{F}_{3}, 1060=0.17$. By inspecting Table 8, it can be seen that Asians and males reported the most Archetypal Dreams and Caucasians and females the least. Night Terrors also showed both a main effect for ethnicity $\underline{F}_{3}, 1043=6.46, \mathrm{p}<.001$ and gender $E_{1,1043}=3.78, \mathrm{p}=.05$ and again the gender by ethnicity interaction was not significant (i.e., $\underline{F}_{3}, 1043=0.88$ ) this time it was African-Americans and females reporting the most Night Terrors and Caucasian and males the least. Data for Fantastic Nightmares showed only a main effect for gender $\underline{F}_{1,1060}=52.36, p<.001$. The main effect for ethnicity and the gender by ethnicity interaction were not significant, $\underline{F}_{3}, 1060=1.41$ and 
$\underline{F}_{3}, 1060=1.89$, respectively. As can be seen in Table 8, women are more likely to report Fantastic Nightmares than men. Prelucid Dreams also showed a main effect for gender $\underline{F}_{1,1060}=7.57, p=.006$, but the main effect for ethnicity and the gender by ethnicity interaction were not significant (i.e., $\underline{F}_{3}, 1060=1.13$ and $\underline{F}_{3}, 1060=1.96$, respectively) again women are more likely to report Prelucid Dreams than men. For Post Traumatic Nightmares, the main effect for gender was significant $\mathbb{F}_{1,1043}=9.52, \mathrm{D}=$ .002) but the main effect for ethnicity and the gender by ethnicity interaction were not significant (i.e., $\underline{F}_{3}, 1043=0.20$ and $\underline{F}_{3}, 1043=1.34$, receptively). By inspecting Table 8, it can be seen that women are more likely to report Post Traumatic Nightmares than men. The last two variables, lucid and control dreams, showed no significant differences. In general, these data coincide with the findings of Tan and Hicks, 1995, that stated that women reported more Night Terrors, Fantastic Nightmares and Post Traumatic Nightmares than men and are partially consistent with the findings of Domino et al. (1985) and Domino (1986) that found a significant main effect for countries and negative dream affect but no gender differences.

\section{Sleep Problems}

Table 9 presents the means and standard deviations for each ethnic by gender group for the Epworth Sleepiness Scale, the Stanford Sleepiness Scale and the Coren Insomnia Scale. Separate analyses of the data for each measure are considered in the following paragraph. 
Table 9

Means and Standard Deviations of Sleep Problems for Ethnicity and Gender

\section{ESS}

SSS

Ethnicity

\begin{tabular}{llrrr} 
African- & Males & $10.59 \pm 3.96$ & $3.08 \pm 1.49$ & $27.98 \pm 5.86$ \\
American & Females & $10.82 \pm 3.71$ & $3.29 \pm 1.64$ & $30.57 \pm 7.11$ \\
$\underline{N}=105$ & Total & $10.71 \pm 3.84$ & $3.18 \pm 1.56$ & $29.27 \pm 6.48$ \\
& & & & \\
& Males & $9.47 \pm 3.64$ & $3.20 \pm 1.59$ & $29.07 \pm 5.96$ \\
Asian & Females & $9.64 \pm 3.88$ & $3.31 \pm 1.59$ & $29.05 \pm 6.28$ \\
$\underline{N}=450$ & Total & $9.55 \pm 3.76$ & $3.25 \pm 1.59$ & $29.06 \pm 6.12$ \\
& & & & \\
& Males & $7.88 \pm 3.58$ & $2.85 \pm 1.30$ & $27.54 \pm 6.56$ \\
Caucasian & Females & $10.02 \pm 4.09$ & $2.98 \pm 1.15$ & $29.25 \pm 5.88$ \\
$\underline{N}=311$ & Total & $8.95 \pm 3.83$ & $2.92 \pm 1.23$ & $28.40 \pm 6.22$ \\
& & & & \\
& Males & $8.98 \pm 4.58$ & $3.01 \pm 1.51$ & $27.72 \pm 6.23$ \\
Hispanic & Females & $9.61 \pm 3.84$ & $3.22 \pm 1.48$ & $29.42 \pm 6.45$ \\
$\underline{N}=224$ & Total & $9.29 \pm 4.21$ & $3.12 \pm 1.50$ & $28.57 \pm 6.34$ \\
\hline
\end{tabular}

Note. The lower the score, the lower the incidence of a sleep problem.

Data for the ESS showed a main effect for both variables (ethnicity $\underline{F}_{3}, 941=4.63$, $\mathrm{p}=.003$, gender $\left.\underline{F}_{1,941}=9.54, \mathrm{R}=.002\right)$ as well as an interaction $\left(F_{3}, 941=4.96\right.$, $p=.002$ ). In examining the reason for the significant main effects and interaction, as shown in Table 9, Caucasian males displayed the least propensity for sleep and AfricanAmerican females the greatest propensity for sleep. Further, in general, women showed a greater propensity for sleep than men. Data for the SSS showed a main effect for ethnicity $\underline{F}_{3,941}=2.76, \mathrm{p}=.04$, Caucasians reported feeling most alert and Asians reported 
feeling least alert, but the main effect for gender and the gender by ethnicity interaction were not significant (i.e., $\underline{F}_{1,941}=2.64$ and $\underline{F}_{3}, 941=0.08$, receptively). Since the SSS provides an index of sleepiness, these data fit nicely with another finding of this study, that is, that Caucasians sleep the most and Asians the least. The insomnia data (CIS) showed a main effect for gender $F_{1}, 941=7.56, \mathrm{D}=.006$ and again no main effect for ethnicity or gender by ethnicity interaction (i.e., $\underline{F}_{3}, 941=0.89$ and $\underline{F}_{3,941}=2.42$, respectively), women have more of a problem with insomnia than men. Since the CIS is a more global scale, the total score may mask some of the specific sleep factors that appear to differentiate the ethnic groups used in this study.

Table 10 presents the means and standard deviations for each ethnic by gender group for the seven subscales and the global score of the Pittsburgh Sleep Quality Index. As well as the responses by individuals in each ethnic group and gender to these questions: "How many nights per week do you have trouble falling asleep?" and "How many nights per week do you have trouble staying asleep?". Separate analyses of the data for each subscale as well as the global score and the two questions are considered in the following paragraph. 
Table 10

Means and Standard Deviations of More Sleep Problems for Ethnicity and Gender

\begin{tabular}{|c|c|c|c|c|c|c|}
\hline & & $\begin{array}{l}\text { PSQ11- } \\
\text { Sleep } \\
\text { Quality }\end{array}$ & $\begin{array}{l}\text { PSQ12- } \\
\text { Sleep } \\
\text { Latency }\end{array}$ & $\begin{array}{l}\text { PSQI3- } \\
\text { Sleep } \\
\text { Duration }\end{array}$ & $\begin{array}{c}\text { PSQ14- } \\
\text { Sleep } \\
\text { Efficiency }\end{array}$ & $\begin{array}{c}\text { PSQ15- } \\
\text { Sleep } \\
\text { Disturbance }\end{array}$ \\
\hline \multicolumn{7}{|l|}{ Ethnicity } \\
\hline $\begin{array}{l}\text { African- } \\
\text { American } \\
\underline{N}=105\end{array}$ & $\begin{array}{l}\text { Males } \\
\text { Females } \\
\text { Total }\end{array}$ & $\begin{array}{l}1.14 \pm .63 \\
1.23 \pm .69 \\
1.18 \pm .66\end{array}$ & $\begin{array}{l}1.09 \pm 1.04 \\
1.08 \pm 1.00 \\
1.09 \pm 1.02\end{array}$ & $\begin{array}{l}1.09 \pm .82 \\
1.03 \pm .92 \\
1.06 \pm .87\end{array}$ & $\begin{array}{l}.28 \pm .69 \\
.39 \pm .71 \\
.34 \pm .70\end{array}$ & $\begin{array}{l}1.13 \pm .59 \\
1.32 \pm .57 \\
1.23 \pm .58\end{array}$ \\
\hline $\begin{array}{l}\text { Asian } \\
\underline{N}=450\end{array}$ & $\begin{array}{l}\text { Males } \\
\text { Females } \\
\text { Total }\end{array}$ & $\begin{array}{l}1.21 \pm .66 \\
1.15 \pm .66 \\
1.18 \pm .66\end{array}$ & $\begin{array}{l}1.25 \pm .96 \\
1.19 \pm .97 \\
1.22 \pm .97\end{array}$ & $\begin{array}{l}1.01 \pm .77 \\
1.06 \pm .82 \\
1.03 \pm .79\end{array}$ & $\begin{array}{l}.23 \pm .59 \\
.32 \pm .68 \\
.28 \pm .64\end{array}$ & $\begin{array}{l}1.24 \pm .54 \\
1.17 \pm .49 \\
1.20 \pm .52\end{array}$ \\
\hline $\begin{array}{l}\text { Caucasian } \\
\underline{N}=311\end{array}$ & $\begin{array}{l}\text { Males } \\
\text { Females } \\
\text { Total }\end{array}$ & $\begin{array}{l}1.06 \pm .64 \\
1.11 \pm .56 \\
1.09 \pm .60\end{array}$ & $\begin{array}{l}1.06 \pm .94 \\
1.15 \pm .89 \\
1.10 \pm .92\end{array}$ & $\begin{array}{l}.82 \pm .74 \\
.70 \pm .69 \\
.76 \pm .71\end{array}$ & $\begin{array}{l}.18 \pm .40 \\
.32 \pm .63 \\
.25 \pm .61\end{array}$ & $\begin{array}{l}1.10 \pm .45 \\
1.15 \pm .44 \\
1.13 \pm .44\end{array}$ \\
\hline $\begin{array}{l}\text { Hispanic } \\
N=224\end{array}$ & $\begin{array}{l}\text { Males } \\
\text { Females } \\
\text { Total }\end{array}$ & $\begin{array}{l}1.13 \pm .67 \\
1.16 \pm .70 \\
1.14 \pm .68\end{array}$ & $\begin{array}{l}1.02 \pm .85 \\
1.25 \pm .98 \\
1.14 \pm .92\end{array}$ & $\begin{array}{l}.94 \pm .72 \\
.88 \pm .86 \\
.91 \pm .79\end{array}$ & $\begin{array}{l}.30 \pm .65 \\
.36 \pm .71 \\
.33 \pm .68\end{array}$ & $\begin{array}{l}1.12 \pm .52 \\
1.20 \pm .44 \\
1.16 \pm .48\end{array}$ \\
\hline
\end{tabular}




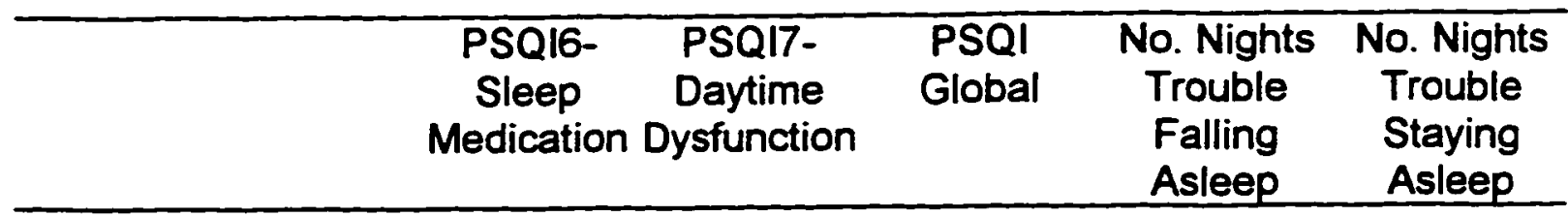

Ethnicity

\begin{tabular}{lllllll} 
African- & Males & $.07 \pm .26$ & $1.07 \pm .89$ & $5.80 \pm 2.71$ & $3.91 \pm 1.76$ & $2.85 \pm 1.21$ \\
American & Females & $.33 \pm .79$ & $1.13 \pm .71$ & $6.44 \pm 3.11$ & $3.75 \pm 1.80$ & $4.11 \pm 2.18$ \\
$\underline{N}=105$ & Total & $.20 \pm .52$ & $1.10 \pm .80$ & $6.12 \pm 2.91$ & $3.83 \pm 1.78$ & $3.48 \pm 1.70$ \\
& & & & & & \\
& Males & $.13 \pm .49$ & $1.17 \pm .78$ & $6.17 \pm 2.51$ & $3.51 \pm 1.79$ & $2.95 \pm 1.74$ \\
Asian & Females & $.05 \pm .23$ & $1.20 \pm .79$ & $6.04 \pm 2.59$ & $3.34 \pm 1.63$ & $3.15 \pm 1.65$ \\
$\underline{N}=450$ & Total & $.09 \pm .36$ & $1.19 \pm .78$ & $6.10 \pm 2.55$ & $3.42 \pm 1.71$ & $3.05 \pm 1.69$ \\
& & & & & & \\
& Males & $.15 \pm .53$ & $1.11 \pm .73$ & $5.43 \pm 2.40$ & $3.86 \pm 1.87$ & $4.10 \pm 1.79$ \\
Caucasian & Females & $.15 \pm .45$ & $1.23 \pm .70$ & $5.75 \pm 2.34$ & $3.07 \pm 1.43$ & $3.89 \pm 2.01$ \\
$\underline{N}=311$ & Total & $.15 \pm .50$ & $1.17 \pm .72$ & $5.59 \pm 2.37$ & $3.47 \pm 1.65$ & $3.99 \pm 1.90$ \\
& & & & & & \\
& Males & $.12 \pm .39$ & $1.07 \pm .75$ & $5.58 \pm 2.47$ & $3.36 \pm 1.68$ & $3.31 \pm 1.49$ \\
Hispanic & Females & $.11 \pm .41$ & $1.16 \pm .78$ & $6.04 \pm 2.54$ & $3.57 \pm 1.72$ & $3.42 \pm 1.62$ \\
$\mathbf{N}=224$ & Total & $.11 \pm .40$ & $1.11 \pm .76$ & $5.81 \pm 2.50$ & $3.46 \pm 1.70$ & $3.36 \pm 1.55$ \\
\hline Note. PSQI values; $0=$ no difficulty to $3=$ severe difficulty.
\end{tabular}

Sleep duration (PSQI3) data showed a main effect for ethnicity $\underline{F}_{3}, 1043=9.58$, $\underline{p}<.001$ but the main effect for gender and the gender by ethnicity interaction were not significant, i.e. $\underline{F}_{1}, 1043=0.13$ and $\underline{F}_{3}, 1043=1.03$, respectively. By inspecting Table 10 , it can be seen that African-Americans displayed the most problems with sleep duration and Caucasians the least. These data partially correspond to the Domino et al. (1985) and Domino (1986) studies that found significant main effects for countries and length of sleep and another finding of this study that stated Caucasians slept the most number of hours and felt that they got all the sleep they needed. Data for habitual sleep efficiency (PSQI4), which is a percentage of the number of hours slept and the actual number of hours spent in bed, showed a main effect for gender $\underline{F}_{1,860}=5.27, p=.02$, women being less efficient, 
and no main effect for ethnicity or gender by ethnicity interaction, i.e., $\underline{F}_{3}, 860=0.81$ and $\underline{F}_{3,860}=0.89$, respectively. Data for sleep disturbances (PSQI5) showed no main effects for ethnicity or gender (i.e., $\underline{F}_{3}, 860=1.19$ and $\underline{F}_{1,860}=0.30$, respectively) but an interaction $\underline{F}_{3}, 860=1.98, p=.02$. As is shown in Table 10, it can be seen that AfricanAmerican women reported the highest difficulty with sleep disturbances and Caucasian men the lowest difficulty with sleep disturbances. This data is partially consistent with that of Domino et al. (1985) and Domino (1986) that found that women reported lighter sleep than men. Use of sleeping medications (PSQI6) data showed a main effect for ethricity $\underline{F}_{3,860}=5.75, \mathrm{p}=.001$ and no main effect for gender, i.e., $\underline{F}_{1,860}=.52$ but an interaction $\underline{F}_{3}, 860=3.69, \mathrm{p}=.01$. By inspecting Table 10, it can be seen that AfricanAmerican women also had the highest use of sleeping medications. With regards to data on the number of nights there was trouble staying asleep there was a main effect for ethnicity $\underline{F}_{3}, 75=5.56, p=.002$ but the main effect for gender and the gender by ethnicity interaction were not significant (i.e., $\underline{F}_{1,75}=0.33$ and $\underline{F}_{3}, 75=1.58$, respectively). This data partially correspondes to the data by the Domino studies that reported significant main effects for countries and depth of sleep and sleep irregularity. Caucasians reported the most problems with staying asleep and Asians reported the least problems. The Pittsburgh Sleep Quality Index data for variables: PSQI1- subjective sleep quality, PSQI2sleep latency, PSQI7- daytime dysfunction and the PSQI global, as well as the number of nights having trouble falling sleep, showed no significant differences. The lack of significant differences on the PSQI2-sleep latency data is inconsistent with that of Domino et al. (1985) and Domino (1986) that found a significant main effect for gender and latency of sleep.

Table 11 is a set of contingency tables showing the frequency of yes-no responses by individuals in each ethnic group and gender to these questions: "Have others told you that 
you snore while you are sleeping?", "Do you experience TMJ problems?", "Do you ever experience bruxism (teeth grinding)?", "Do you have trouble falling asleep?" and "Do you have trouble staying asleep for the entire sleep period?".

Table 11

The Frequency of Self-Reported Sleep Problems for Ethnicity and Gender

\begin{tabular}{|c|c|c|c|c|c|c|}
\hline \multirow[b]{2}{*}{ Group } & \multicolumn{2}{|c|}{$\begin{array}{l}\text { Snoring } \\
(\mathrm{N}=1098)\end{array}$} & \multicolumn{2}{|c|}{$\begin{array}{l}\text { TMJ } \\
(\underline{N}=924)\end{array}$} & \multicolumn{2}{|c|}{$\begin{array}{l}\text { Bruxism } \\
(\underline{N}=1095)\end{array}$} \\
\hline & Yes & No & Yes & No & Yes & No \\
\hline African-American & 45 & 61 & 1 & 80 & 10 & 96 \\
\hline Asian & 203 & 251 & 9 & 371 & 111 & 341 \\
\hline Caucasian & 97 & 214 & 21 & 253 & 72 & 240 \\
\hline \multirow[t]{2}{*}{ Hispanic } & 90 & 137 & 5 & 184 & 38 & 187 \\
\hline & \multicolumn{2}{|c|}{$\begin{array}{l}\text { Snoring } \\
(\underline{N}=1097)\end{array}$} & \multicolumn{2}{|c|}{$\begin{array}{l}\text { TMJ } \\
(\underline{N}=923)\end{array}$} & \multicolumn{2}{|c|}{$\begin{array}{l}\text { Bruxism } \\
(\underline{N}=1094)\end{array}$} \\
\hline Group & Yes & No & Yes & No & Yes & No \\
\hline Male & 240 & 255 & 4 & 418 & 94 & 400 \\
\hline Female & 194 & 408 & 32 & 469 & 137 & 463 \\
\hline
\end{tabular}




\begin{tabular}{|c|c|c|c|c|}
\hline \multirow[b]{2}{*}{ Group } & \multicolumn{2}{|c|}{$\begin{array}{l}\text { Trouble Falling Asleep } \\
\qquad \underline{N}=1098)\end{array}$} & \multicolumn{2}{|c|}{$\begin{array}{l}\text { Trouble Staying Asleep } \\
\qquad \underline{N}=1100)\end{array}$} \\
\hline & Yes & No & Yes & No \\
\hline African-American & 32 & 75 & 35 & 72 \\
\hline Asian & 165 & 287 & 101 & 353 \\
\hline Caucasian & 94 & 218 & 87 & 225 \\
\hline \multirow[t]{2}{*}{ Hispanic } & 97 & 130 & 64 & 163 \\
\hline & \multicolumn{2}{|c|}{$\begin{array}{l}\text { Trouble Falling Asleep } \\
\qquad \underline{N}=1097)\end{array}$} & \multicolumn{2}{|c|}{$\begin{array}{l}\text { Trouble Staying Asleep } \\
\qquad(\underline{N}=1099)\end{array}$} \\
\hline Group & Yes & No & Yes & No \\
\hline Male & 166 & 330 & 120 & 376 \\
\hline Female & 222 & 379 & 167 & 436 \\
\hline
\end{tabular}

Data for snoring showed significant differences for both variables (ethnicity $\chi^{2}(3)=$ $14.52, \mathrm{p}=.002$ and $\phi^{\prime}=.12$, gender $\chi^{2}(1)=30.03, \mathrm{p} \leq .001$ and $\left.\phi^{\prime}=.17\right)$. By inspecting Table 11, it can be seen that men and Asians reported the highest incidences of snoring while women and African-Americans the lowest incidences. It is interesting to note that overall $60 \%$ of the participants reported that they did not snore which coincides with the finding in the study by Hicks, Bautista and McCullough (1994) that stated $51.4 \%$ of their young adult participants reported that they never snore. Data for TMJ also showed significant differences for both variables (ethnicity $\chi^{2}(3)=15.08, p=.002$ and $\phi^{\prime}=.13$, gender $\chi^{2}(1)=18.08, \mathrm{p}=.001$ and $\phi^{\prime}=.14$ ). Again by inspecting Table 11 , it can be seen that more Caucasians and women reported problems with TMJ. It is interesting to note that overall $96.5 \%$ of the participants responded no to the question "Do you experience TMJ problems?". This could be due to the fact that many people do not know what TMJ 
is. Bruxism data showed a significant difference for ethnicity $\chi^{2}(3)=15.04, p=.002$ and $\phi^{\prime}=.12$ but no significant difference for gender (i.e., $\chi^{2}(1)=2.356$ ). Asians reported the most problems with bruxism and African-Americans the least. Having trouble falling asleep also showed a significant difference for only ethnicity $\chi^{2}(3)=10.79, p=.01$ and $\phi^{\prime}=.10$ and no significant difference for gender (i.e., $\chi^{2}(1)=1.431$ ). Hispanics reporting the most trouble falling asleep. Data for having trouble staying asleep showed no significant differences.

\section{Sleep Knowledge and Hygiene}

Table 12 presents the means and standard deviations for each ethnic by gender group for sleep knowledge and sleep hygiene measured by the Sleep Hygiene Questionnaire. Separate analyses of the data for each measure are considered in the following paragraphs. 
Table 12

Means and Standard Deviations of Sleep Knowledge and Hygiene Measures for Ethnicity and Gender

\begin{tabular}{cccc}
$\begin{array}{c}\text { General Sleep } \\
\text { Knowledge }\end{array}$ & $\begin{array}{c}\text { Caffeine } \\
\text { Knowledge }\end{array}$ & $\begin{array}{c}\text { Sleep } \\
\text { Hygiene } \\
\text { Knowledge }\end{array}$ & $\begin{array}{c}\text { Sleep Hygiene } \\
\text { Practices }\end{array}$ \\
\hline
\end{tabular}

Ethnicity

\begin{tabular}{llllll} 
African- & Males & $56.30 \pm 13.77$ & $61.66 \pm 12.57$ & $26.49 \pm 4.96$ & $30.65 \pm 9.68$ \\
American & Females & $58.88 \pm 14.21$ & $62.52 \pm 13.61$ & $25.79 \pm 4.20$ & $29.44 \pm 9.97$ \\
$\underline{N}=102$ & Total & $57.59 \pm 13.99$ & $62.09 \pm 13.09$ & $26.14 \pm 4.58$ & $30.05 \pm 9.82$ \\
& & & & & \\
& Males & $59.29 \pm 14.72$ & $62.79 \pm 13.47$ & $25.63 \pm 4.97$ & $29.58 \pm 10.03$ \\
Asian & Females & $61.71 \pm 13.94$ & $64.41 \pm 12.90$ & $25.57 \pm 5.14$ & $28.33 \pm 9.72$ \\
$\underline{N}=449$ & Total & $60.50 \pm 14.10$ & $63.60 \pm 13.19$ & $25.60 \pm 5.06$ & $28.95 \pm 9.88$ \\
& & & & & \\
& Males & $64.84 \pm 12.67$ & $67.20 \pm 12.76$ & $24.78 \pm 4.97$ & $24.94 \pm 10.70$ \\
Caucasian & Females & $69.06 \pm 12.33$ & $70.77 \pm 12.86$ & $23.72 \pm 5.00$ & $26.09 \pm 8.85$ \\
$\underline{N}=312$ & Total & $66.95 \pm 12.50$ & $68.99 \pm 12.81$ & $24.25 \pm 4.99$ & $25.52 \pm 9.77$ \\
& & & & & \\
& Males & $56.40 \pm 16.00$ & $61.61 \pm 13.02$ & $26.13 \pm 4.78$ & $27.14 \pm 9.32$ \\
Hispanic & Females & $61.18 \pm 13.72$ & $60.66 \pm 11.63$ & $26.49 \pm 4.98$ & $28.02 \pm 9.60$ \\
$\mathbf{N}=227$ & Total & $58.79 \pm 14.86$ & $61.14 \pm 12.33$ & $26.31 \pm 4.88$ & $27.58 \pm 9.46$ \\
\hline
\end{tabular}

Note. For the GSK and the CK scales, the higher the score, the greater the knowledge.

For the SHK and SHP scales the lower the score, the greater the knowledge.

The data for general sleep knowledge showed both a main effect for ethnicity $\underline{F}_{3}, 1083$ $=22.23, \mathfrak{p}<.001$ and gender $\underline{F}_{1,1083}=16.45, \mathfrak{p}<.001$ but the gender by ethnicity interaction was not significant, i.e., $\underline{F}_{3}, 1083=0.69$. By inspecting Table 12, it can be seen that Caucasians and women reported to have the most general sleep knowledge and African-Americans and men reported to have the least general sleep knowledge. Data for caffeine knowledge also showed both a main effect for ethnicity $\underline{F}_{3}, 956=20.41, \underline{p}<.001$ 
and gender $\underline{F}_{1}, 956=3.74, p=.05$ and again no gender by ethnicity interaction was significant, i.e., $\underline{F}_{3}, 956=1.62$. In examining the reason for the significant main effects for caffeine knowledge, as are shown in Table 12, Caucasians and women displayed the most caffeine knowledge and Hispanics and men the least caffeine knowledge. Data for sleep hygiene knowledge showed only a main effect for ethnicity $\underline{F}_{3,956}=9.28, \underline{p}<.001$, the main effect for gender and the gender by ethnicity interaction were not significant, (i.e., $\underline{F}_{1,956}=1.27$ and $\underline{F}_{3}, 956=1.45$, respectively). By inspecting Table 12 it can be seen that Caucasians reported the most sleep hygiene knowledge and Hispanics the least. Data for sleep hygiene practices also showed a main effect only for ethnicity $\underline{F}_{3}, 956=$ $7.16, p<.001$ and the main effect for gender and the gender by ethnicity interaction were not significant, i.e., $\underline{F}_{1,956}=0.11$ and $\underline{F}_{3}, 956=1.55$, respectively. Again, in examining the reason for the significant main effect for sleep hygiene practices, as are shown in Table 12, Caucasians displayed the best hygiene practices and African-Americans the worst. Sleep hygiene knowledge was positively correlated with sleep hygiene practices $(\tau=0.12$, $\mathrm{p}<.001)$ and in general by inspecting Table 12 it can be seen that there is a relationship between sleep knowledge and sleep hygiene practices, i.e., the group who displayed the most knowledge also had the best sleep hygiene practices.

By inspecting the sleep knowledge and practice data and the sleep probiem data some general trends are apparent. Caucasians reported the best general sleep knowledge followed by Asians, Hispanics and African-Americans. Caucasians also reported the best sleep hygiene knowledge followed by Asians, African-Americans and Hispanics. In regards to sleep hygiene practices Caucasians have the best sleep hygiene practices, followed closely by Asians, Hispanics and African-Americans. Looking at sleep problems in general, excluding dental problems, this trend continues with Caucasians reporting the least amount of problems, followed by Hispanics, Asians and African-Americans. It is also 
interesting to note that the data for sleep length and number of naps aiso followed this general trend where Caucasians reported sleeping the longest and taking the least number of naps, followed by Hispanics and Asians and then African-Americans reporting the shortest sleep lengths and the most number of naps.

\section{Conclusions}

The clear conclusion that can be drawn from this study is that both ethnicity and gender are related to several parameters of sleep. In the following paragraphs specific conclusions are given for the sleep-related groups of variables that were included in this study.

\section{Sleep Habits}

Significant results for ethnicity were computed for 5 out of the 7 sleep habit variables, i.e., the Owl and Lark Questionnaire, sleep length, getting all the sleep needed, satisfaction with sleep and taking naps and one significant main effect for gender, i.e., males reported taking more naps per month.

\section{Dreams}

For the dream variables, significant main effects for ethnicity were obtained for 3 out of the 11, i.e., number of dreams, Archetypal Dreams and Night Terrors. Eight significant results were computed for gender, i.e., females reported remembering their dreams more, having more valuable dreams, experiencing more pain while dreaming, having more Night Terrors, Fantastic Nightmares, Prelucid and Post-Traumatic Dreams. Males reported more Archetypal Dreams.

\section{Sleep Problems}

Significant results for ethnicity were obtained for 9 out of the 18 sleep problem variables, i.e., the Epworth Sleepiness Scale, the Stanford Sleepiness Scale, sleep duration, use of sleep medication, trouble falling asleep and number of nights there was trouble 
falling asleep, snoring, bruxism, and TMJ. There were 5 significant results for gender, i.e., females reported more sleep problems on the Epworth Sleepiness Scale and the Coren Insomnia Scale, less sleep efficiency and more troubles with TMJ. Males reported a higher incidence of snoring. There were also interactions for 3 variables, the Epworth Sleepiness Scale, sleep disturbances and use of sleep medication. There is some disagreement between the findings for the ESS and the SSS. While in both cases Caucasians were the least tired and most alert, African-Americans reported being most tired on the ESS and Asians reported feeling less alert on the SSS. This could be due to the fact that the scales measure different kinds of sleepiness, i.e., the ESS measures the likelihood of a subject falling asleep in eight situations whereas the SSS measures how sleepy a subject is at the time of filling out the scale. In general key sleep problems tend to be; daytime sleepiness, sleep duration including such factors as length of sleep and sleep disturbances and dental problems, i.e., snoring, bruxism and TMJ.

\section{Sleep Knowledge and Hygiene}

Significant main effects for ethnicity were computed for all of the sleep knowledge variables, i.e., general sleep knowledge, caffeine knowledge, sleep hygiene knowledge and sleep hygiene practices and 2 main effects for gender, i.e., females displayed an increase knowledge in the areas of general sleep and caffeine.

Overall there is a tendency toward insomnia, a score of $\leq \mathbf{2 5}$ on the Coren Insomnia Scale indicates low incidence, which was $29 \%$ of our population, and our total population mean was 28.85. Young adults, no matter of ethnicity or gender, do not have accurate knowledge of general sleep information or sleep hygiene practices. For the general sleep knowledge measure the mean percents correct were low, i.e., $58 \%$ for African-Americans, $61 \%$ for Asians, $67 \%$ for Caucasians and $59 \%$ for Hispanics. There is a general relationship between sleep knowledge and sleep hygiene practices, those groups who 
scored the highest on the sleep knowledge questions also displayed the best sleep hygiene practices. A clear implication from this data is that more stress should be placed on incorporating sleep hygiene practices and sleep knowledge into formal education. Since this is such a new area of study, continued research needs to be done. 


\section{References}

Buysse, D. J., Reynolds III, C. F., Monk, T. H., Berman, S. R., \& Kuper, D. J. (1989). The pittsburgh sleep quality index: A new instrument for psychiatric practice and research. Psychiatry Research, 28, 193-213.

Coren, S. (1988). Prediction of insomnia from arousability predisposition scores: Scale development and cross-validation. Behavior Research and Therapy, 26, 415-420.

Domino, G. (1986). Sleep habits in the elderly: A study of three Hispanic cultures. Joumal of Cross-Cultural Psychology, 17(1), 109-120.

Domino, G., Romero, M., Blair, G., Villalobos, S., Suriano, T., \& Bridges, A. (1985). Cross-cultural aspects of sleep in the elderly. Research on Aging 7(2), 195-208.

Friedman, M., \& Rosenman, R. H. (1977). The key cause: Type A behavior pattern. In A. Monet \& R. S. Lazarus (Eds.), Stress and coping. New York: Columbia University Press.

Glass, D. C. (1977). Behavior patterns, stress, and coronary disease. Hillsdale, NJ: Erlbaum.

Gislason, T., Aberg, H., \& Taube, A. (1987). Snoring and systemic hypertension. An epidemiological study. Acta Medica Scandinavica, 222, 415-421.

Hauri, P. (1977). Current concepts: The sleep disorders. Kalamazoo: Upjohn.

Hicks, R. A., Bautista, J., \& McCullough, M. (1994). Snoring may be linked to culture. Medical Hypotheses, 42, 24-26.

Hicks, R. A., Conti, P., \& Pellegrini, R. J. (1992). The incidence of sleep problems among Type A and Type B college students: Changes over a ten-year period (19821992). Perceptual and Motor Skills, $75,746$.

Hicks, R. A., Lucero, K., \& Mistry, R. (1991). Dreaming and habitual sleep duration. Perceptual and Motor Skills, 72, 1-2.

Hicks, R. A., \& McCullough, M. (1992, April). The self-reported prevalence of snoring in college students. Poster session presented at the annual meeting of the Western Psychological Association, Portland, OR. 
Hicks, R. A., Mistry, R., Lucero, K., Lee, L., \& Pellegrini, R. (1989). The sleep duration and sleep satisfaction of college students: Striking changes over the last decade (1978-1988). Perceptual and Motor Skills, 68, 806.

Hicks, R. A., Mistry, R., Lucero, K., Marical, C., \& Pellegrini, R. (1990). Selfreported sleep durations of college students: Normative data for 1978-79 and 1988-89. Perceptual and Motor Skills, $70,370$.

Hicks, R. A., \& Pellegrini, R. J. (1982). Sleep problems and type A-B behavior in college students. Psychological Reports, 51, 196.

Hicks, R. A., \& Pellegrini, R. J. (1991). The changing sleep habits of college students. Perceptual and Motor Skills, 72, 1106.

Hicks, R. A., Pellegrini, R. J., Martin, S., Garbesi, L., Elliot, D., \& Hawkins, J. (1979). Type A behavior and normal habitual sleep duration. Bulletin of the Psychonomic Society, 14, 185-186.

Hoddes, E., Zarcone, V., Smythe, H., Phillips, R., \& Dement, W. C. (1973). Quantification of sleepiness: A new approach. Psychophysiology, 10(4), 431-436.

Horne, J. A., \& Ostberg, O. (1976). A self-assignment questionnaire to determine morningness-eveningness in human circadian rhythms. International Journal of Chronobiology, 4, 97-110.

Johns, M. (1991). A new method for measuring daytime sleepiness: The epworth sleepiness scale. Sleep, 14(6), 540-545.

Koskenvuo, M., Kaprio, J., Telakivi, T., Partinen, M., Heikkila, K., \& Sarna, S. (1987). Snoring as a risk factor for ischaemic heart disease and stroke in men. British Medical Journal, 294, 16-19.

Lacks, P. (1987). Behavioral treatment for persistent insomnia. Elmsford, NY: Pergamon Press.

Lucero, K., \& Hicks, R. A. (1990). Relationship between habitual sleep duration and diet. Perceptual and Motor Skills, 71, 1377-1378.

Lucero, K., Hicks, R. A., Mistry, R., \& Bautista, J. (1991). The relationship between sleep and eating behavior in college students. Higher Education Abstracts, 25(2), 168.

Lugaresi, E., Cirignotta, F., Coccagna, G., \& Piana, C. (1980). Some epidemiological data on snoring and cardiocirculatory disturbances. Sleep, $3,221-224$. 
Margiotta, E. W., Davilla, D. A., \& Hicks, R. A. (1990). Type A-B behavior and the self-report of daily hassles and uplifts. Perceptual and Motor Skills, 70, 777-778.

Milter, E. A., \& Milter, M. M. (1990). 101 questions about sleep and dreams (3rd ed.). Del Mar, CA: Wakefulness-Sleep Education and Research Foundation.

Perez-Padilla, R. (1991). Why do humans snore so commonly? APSS Newsletter. 6, 37.

Schoicket, S. L., Bertelson, A. D., \& Lacks, P. (1988). Is sleep hygiene a sufficient treatment for sleep-maintenance insomnia? Behavior Therapy, 19, 183-190.

Spadafora, A., \& Hunt, H. T. (1990). The multiplicity of dreams: Cognitive-Affective correlates of lucid, archetypal, and nightmare dreaming. Perceptual and Motor Skills, 71, 627-644.

Tan, Vickie, L., \& Hicks, Robert, A. (1995). Type A-B behavior \& nightmare types among college students. Perceptual and Motor Skills, 81(1), 15-19. 
Appendix A

Owl and Lark Questionnaire

Instructions:

1. Please read each question very carefully before answering.

2. Answer ALL questions.

3. Answer questions in numerical order.

4. Each question should be answered independently of others. DO NOT go back and check your answers.

5. All questions have a selection of answers. For each question place a cross alongside ONE answer only. Some questions have a scale instead of a selection of answers. Place a cross at the appropriate point along the scale.

1. Considering only your own "feeling best" rhythm, at what time would you get up if you were entirely free to plan your day?

\begin{tabular}{llllllll}
\hline $5 \mathrm{AM}$ & 6 & 7 & 8 & 9 & 10 & 11 & 12
\end{tabular}

2. Considering only your own "feeling best" rhythm, at what time would you go to bed if you were entirely free to plan your evening?

\begin{tabular}{llllllll}
\hline 8 PM & 9 & 10 & 11 & $12 \mathrm{AM}$ & 1 & 2 & 3
\end{tabular}

3. If there is a specific time at which you have to get up in Not at all dependent the morning, to what extent are you dependent on being Slightly dependent woken up by an alarm clock?

Fairly dependent

Very dependent

4. Assuming adequate environmental conditions, how easy do you find getting up in the mornings?

Not at all easy

Not very easy

Fairly easy

Very easy

5. How alert do you feel during the first half hour after

Not at all alert having woken in the mornings?

Slightly alert

Fairly alert

Very alert

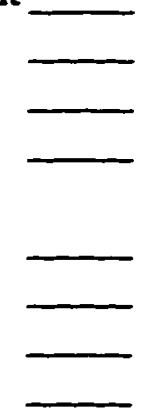




\section{Appendix A (cont'd)}

6. How is your appetite during the first half hour after having woken in the mornings?

Very poor

Fairly poor

Fairly good

Very good

7. During the first half hour after having woken in the morning, how tired do you feel?

Very tired

Fairly tired

Fairly refreshed

Very refreshed

8. When you have no commitments the next day, at what time do you go to bed compared to your usual bedtime?

Seldom or never

later

Less than 1 hour

later

1-2 hours later

More than 2 hours

later

9. You have decided to engage in some physical exercise.

A friend suggests that you do this 1 hour twice a week and the best time for him is between 7:00-8:00 AM.

Bearing in mind nothing else but your own "feeling best" rhythm how do you think you would perform?

Would be in good

form

Would be in

reasonable form

Would find it

difficult

Would find it very difficult

10. At what time in the evening do you feel tired and as a result in need of sleep?

8PM

10

11

$12 \mathrm{AM}$

l

2

3

11. You wish to be at your peak performance for a test which you know is going to be mentally exhausting and lasting for two hours. You are entirely free to plan your day and considering only your own "feeling

8:00-10:00 AM 11:00 AM-1:00 PM best" rhythm which ONE of the four testing times would you choose?

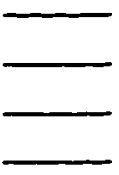


Appendix A (cont'd)

12. If you went to bed at 11:00 PM at what level of tiredness would you be?

13. For some reason you have gone to bed several hours later than usual but there is no need to get up at any particular time the next morning. Which ONE of the following events are you most likely to experience?

14. One night you have to remain awake between 4:00-6:00 AM in order to carry out a night watch. You have no commitments the next day. Which $\mathrm{ONE}$ of the following alternatives will suit you best?

15. You have to do two hours of hard physical work. You are entirely free to plan your day and considering only your own "feeling best" rhythm which ONE of the following items would you choose?

16. You have decided to engage in hard physical exercise. A friend suggests that you do this for 1 hour twice a week and the best time for him is between 10:0011:00 PM. Bearing in mind nothing else but your own "feeling best" rhythm how well do you perform?
Not at all tired

A little tired

Fairly tired

Very tired

Will wake up at usual time and will NOT fall asleep

Will wake up at usual time and will doze thereafter

Will wake up at usual time but will fall asleep again

Will NOT wake up until later than usual

Would NOT go to bed until watch was over

Would take a nap before and sleep after Would take a good sleep before and nap after Would take ALL sleep before watch

8:00-10:00 AM 11:00 AM-1:00 PM 3:00-5:00 PM 7:00-9:00 PM

Would be in good form Would be in reasonable form Would find it difficult Would find it very difficult. 


\section{Appendix B}

\section{Sleep Habits Questionnaire}

Please provide the following information. (Either check correct response or fill in the correct information.)

Female Male Height Weight Age

1. How long do you sleep on an average night?

2. You have been averaging the number of hours of sleep per night given in response to Question 1 for years and/or months.

3. Are you generally satisfied with your sleep each night? Yes No.

4. Do you generally get all of the sleep that you need each night? Yes No.

5. If you have changed the number of hours that you usually sleep, how long did you sleep on an average night before you made this change? hours.

6. How long ago did you make this change? years and/or months.

7. Why did you decide to alter your sleep? (fill in the major reason.)

8. Were you generally satisfied with your sleep before this change? Yes No.

9. Did you generally get all of the sleep that you needed before this change? Yes No.

10. Do you take naps during the day? Yes often and how long? number per month No. If you answered yes, how average minutes per nap.

11. On average, how many dreams do you have each night? 3 more than 3 (give the number 0 2

12. If you dream, are your dreams usually: pleasant, unpleasant, neutral? 


\section{Appendix B (cont'd)}

13. Did you dream last night? pleasant, unpleasant, No. If you had a dream, was it Yes neutral?

14. Do you have trouble falling asleep? Yes No. If you answered yes, on average, how many nights per week do you experience this problem ?

15. Do you have trouble staying asleep for the entire sleep period? Yes No. If you answered yes, on average, how many nights per week do you experience this problem ?

16. Have others told you that you snore while you are sleeping? Yes No.

17. Do you ever experience bruxism (teeth grinding)? Yes No.

18. Do you experience TMJ problems? occur at night during the day Yes both No. If yes, does this usually

These questions are designed to measure certain relationships between how people sleep and dream and their ethnic or cultural background. Please answer each question as best you can.

19. What is your ethnic or racial origin

American Indian

Afro-American

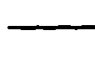

Mexican-American

Other Hispanic
Asian

Pacific Islander

Caucasian

Other (describe)

20. I was Born in (name the country).

21. My parents were born in Mother Father (name the countries)

22. My native language is

23. If English is your second language, how many years have you spoken English? 


\section{Appendix B (cont'd)}

24. If English is your second language, please indicate the language you use when you engage in the following mental activities:

When I dream

When I have a nightmare

When I think about things

When I do math problems in my head

When I am thinking about a stressful situation

25. What language do you speak at home?

26. What language do you speak with your friends?

27. I started to learn English when I was years old.

28. In what language are you most fluent?

29. I remember my dreams Never Rarely Sometimes Often Usually Always.

30. My dreams are valuable experiences Often Usually Always. Never Rarely Sometimes

31. I experience pain while I'm dreaming Never Rarely Sometimes Often Usually Always. 


\section{Appendix C}

\section{Epworth Sleepiness Scale}

How likely are you to doze off or fall asleep in the following situations, in contrast to feeling just tired? This refers to your usual way of life in recent times. Even if you have not done some of these things recently, try to work out how they would have affected you. Use the following scale to choose the most appropriate number for each situation.

$$
\begin{aligned}
& 0=\text { would never doze } \\
& 1=\text { slight chance of dozing } \\
& 2=\text { moderate chance of dozing } \\
& 3=\text { high chance of dozing }
\end{aligned}
$$

Situation

Sitting and reading

Watching TV

Sitting inactive in a public place (e.g. a theater or a meeting)

As a passenger in a car for an hour without a break

Lying down to rest in the afternoon when circumstances permit

Sitting and talking to someone

Sitting quietly after a lunch without alcohol

In a car, while stopped for a few minutes in traffic 
Appendix D

Stanford Sleepiness Scale

Instructions: Circle the number of the statement which best describes your state of sleepiness right now.

1. Feeling active and vital; alert; wide awake.

2. Functioning at a high level, but not at peak; able to concentrate.

3. Relaxed; awake; not at full alertness; responsive.

4. A little foggy; not at peak; let down.

5. Fogginess; beginning to lose interest in remaining awake; slowed down.

6. Sleepiness; prefer to be lying down; fighting sleep; woozy.

7. Almost in reverie; sleep onset soon; lost struggle to remain awake. 


\section{Appendix E}

\section{Coren's Insomnia Scale}

Instructions: This questionnaire deals with a number of common behaviors and selfperceptions. For each question select from among the following response alternatives:

Never (or almost never) Seldom Occasionally Frequently Always (or almost always) Circle the first letter which corresponds to your choice.

1. I experience delayed sleep onset NSOFA

2. I awake during the night N S OFA

3. I awake early in the morning. NSOFA

4. I have nightmares. N S F A

5. I experience restlessness. N S OF A

6. I awake tired N SOFA

7. I get all the sleep that I need. N SOFA

8. I am satisfied with my sleep. N SOF A

9. I feel rested in the morning.

10. When I awake during the night, I have difficulty falling asleep again. NSOFA 11. I snore during my sleep. 


\section{Appendix F}

\section{Pittsburgh Sleep Quality Index}

Instructions: The following questions relate to your usual sleep habits during the past month only. Your answers should indicate the most accurate reply for the majority of days and nights in the past month.

Please answer all questions.

1. During the past month, when have you usually.gone to bed at night?

\section{USUAL BED TIME}

2. During the past month, how long (in minutes) has it usually take you to fall asleep each night?

\section{NUMBER OF MINUTES}

3. During the past month, when have you usually gotten up in the morning?

\section{USUAL GETTING UP TIME}

4. During the past month, how many hours of actual sleep did you get at night? (This may be different than the number of hours you spend in bed.)

\section{HOURS OF SLEEP PER NIGHT}

For each of the remaining questions, check the one best response. Please answer all questions.

5. During the past month, how often have you had trouble sleeping because you...

(a.) Cannot get to sleep within 30 minutes

Not during the past month
Less than once a week
Once or twice a week
Three or more times a week

(b.) Wake up in the middle of the night or early morning

Not during the past month
Less than once a week
Once or twice a week
Three or more times a week 


\section{Appendix F (cont'd)}

(c.) Have to get up to use the bathroom

Not during the past month
Less than once a week
Once or twice a week
Three or more times a week

(d.) Cannot breathe comfortably

Not during the past month
Less than once a week
Once or twice a week

Once or twice a week
Three or more times a week

(e.) Cough or snore loudly

Less than once a week
Not during the past month

(f.) Feel to cold

Not during the past month

(g.) Feel to hot

Not during the past month

Less than once a week
Once or twice a week
Three or more times a week

Once or twice a week

Three or more times a week

Three or more times a week

(h.) Had bad dreams

Not during the past month

Less than once a week
Once or twice a week
Three or more times a week

(i.) Have pain

Not during the past month
Less than once a week
Once or twice a week
Three or more times a week

(j.) Other reason(s), please describe: 


\title{
Appendix F (cont'd)
}

How often during this past month have you had trouble sleeping because of this?

Not during the past month
Less than

once a week
Once or

twice a week
Three or more times a week

6. During the past month, how would you rate your sleep overall?

\author{
Very good \\ Fairly good \\ Fairly bad \\ Very bad
}

7. During the past month, how often have you taken medicine (prescribed or "over the counter") to help you sleep?

Not during the past month
Less than once a week
Once or

twice a week
Three or more times a week

8. During the past month, how often have you had trouble staying awake while driving, eating meals, or engaging in social activity?

Not during the past month
Less than

once a week
Once or

twice a week
Three or more times a week

9. During the past month, how often of a problem has it been for you to keep up enough enthusiasm to get things done?

No problem at all

Only a very slight problem

Somewhat of a problem

A very big problem

10. Do you have a bed partner or roommate?

No bed partner or roommate

Partner/roommate in other room

Partner in same room, but not same bed

Partner in same bed 


\section{Appendix F (cont'd)}

If you have a roommate or bed partner, how often in the past month have they mentioned to you that you have had...

(a.) Loud snoring

Not during the past month

\section{Less than}

once a week
Once or twice a week
Three or more times a week

(b.) Long pauses between breaths while asleep

Not during the past month
Less than once a week
Once or twice a week
Three or more times a week

(c.) Leg twitching or jerking while you sleep

Not during the past month
Less than once a week
Once or twice a week
Three or more times a week

(d.) Episodes of disorientation or confusion during sleep

Not during the past month
Less than once a week
Once or

twice a week
Three or more times a week

(e.) Other restlessness while you sleep; please describe:

Not during the past month
Less than once a week
Once or twice a week
Three or more times a week 


\section{Appendix G}

\section{Sleep Hygiene Questionnaire}

Please provide the following information. (Either circle correct response or fill in the correct information).

1. The normal amount of sleep for adults is?
a. 8 hours
b. 6 hours
c. 10 hours
d. Different for everyone

2. Which condition(s) can affect sleep?
a. Room temperature
b. Noise (i.e. TV or radio)
c. Bedclothes
d. All of the above

3. Everyone dreams.
a. True
b. False

4. When do people dream?
a. In the beginning of the night
b. At the end of the night
c. All throughout the night
d. Not at all

5. People can't get hurt sleepwalking.
a. True
b. False

6. Which has the best sleep-promoting effect?
a. An alcoholic beverage
b. A glass of milk
c. A caffeinated beverage

7. Counting sheep really works.
a. True
b. False 


\section{Appendix G (cont'd)}

8. What is sleep apnea?
a. A sleep disorder in which people are paralyzed during sleep
b. A sleep disorder that occurs because of difficulty in breathing
c. A sleep disorder in which people suffer sleep attacks
d. None of the above

9. Only men snore.
a. True
b. False

10. To help promote sleep when should exercise be done?
a. In the early part of the day
b. In the evening before bedtime
c. Not at all

11. Calories are burned when you sleep.
a. True
b. False

12. If you have trouble falling asleep, what is it that keeps you awake? (circle all that apply to you)
a. Thoughts running through my mind
b. Aches and pains
c. Too much noise
d. Others, please state

13. If you have trouble falling asleep, do you:
a. Just lie in bed
b. Turn on the light and read
c. Get up
d. Others, please state

14. Do you take anything to help you fall asleep?
a. Never or almost never
b. Sometimes
c. Often
d. Always or almost always 
Appendix G (cont'd)

15. If you take something to help you fall asleep, what is it?
a. Medicine prescribed by a doctor
b. Non-prescribed medicine
c. Others, please state

16. How often do you take naps?
a. Rarely or never
b. Less than once a month
c. About once a month
d. 1 or 2 times per week
e. 3 or 4 times a week
f. 5 or more times per week
g. More than once a day

17. Do you have disturbing dreams or nightmares?
a. Never or almost never
b. Sometimes
c. Often
d. Always or almost always

18. Overall, what kind of sleeper are you?
a. Very good
b. Good
c. Average
d. Poor
e. Very poor

19. How much do you smoke each day?
a. None
b. Less than 1 pack
c. 1 pack
d. 2 packs
e. More than 2 packs 


\section{Appendix G (cont'd)}

20. How much coffee, tea, or caffeinated soda do you drink per day? (If you only drink soda, circle soda)
a. None
b. 1 cup or 1 soda
c. 2 or 3 cups or 2 to 3 sodas
d. 3 to 5 cups or 3 to 5 sodas
e. More than 5 cups or 5 sodas
f. Other combination of coffee, tea, or caffeinated soda consumption: Please list how many cups of each coffee, tea, and soda

21. If you are a poor or very poor sleeper, is this because you: (circle the most important reason):
a. Have trouble falling asleep
b. Wake up and have trouble going back to sleep
c. Have disturbing dreams or nightmares
d. Are awakened frequently by noise
e. Wake up early (early morning awakening)
f. Wake up tired
g. Other, please

22. If you are a poor or very poor sleeper, how long have you had a sleep problem?
a. 1 to 6 months
b. 6 months to 1 year
c. 1 to 2 years
d. 3 to 5 years
e. 5 to 10 years
f. As long as you can remember
g. Does not apply to me

23. Were (or are) any of your family members poor sleepers, that is, have sleep problems?
a. Yes
b. No

24. If yes, which family member(s)?
a. Father
b. Mother
c. Brother
d. Sister
e. Does not apply to me 


\section{Appendix G (cont'd)}

25. Have you ever experienced the following? (circle one(s) that you have experienced) ** To state when you experienced each and how often it occurred, please put $C$ for Childhood, A for Adolescence, P for Present and approximately how often it occurred during that period of time.

a. Sleep walking

b. Night terror

c. Body/Head rocking

d. Enuresis (Bedwetting)

e. Sleep talking

26. What kind of sleeper were you when you were a child?
a. Very good
b. Good
c. Average
d. Poor
e. Very poor

27. What kind of sleeper were you in your teens or during high school years?
a. Very good
b. Good
c. Average
d. Poor
e. Very poor

28. Do you snore?
a. Never or almost never
b. Sometimes
c. Every night

29. Have you ever engaged in acts of violence or very dangerous activity while asleep?
a. Never
b. Once or twice
c. Three or more times

30. Do you toss and turn a lot during sleep?
a. Never or rarely
b. Sometimes
c. Often
d. Always

31. How many hours of sleep do you need each night to feel well rested? hours

32. Do you feel that you are getting enough sleep each night?
a. Never or almost never
b. Sometimes
c. Often
d. Always or almost always 


\section{Appendix G (cont'd)}

Please use the following scale and answer each item by writing the appropriate number in the space provided. Note that numbers 1,2 , and 3 indicate degrees of benefit to sleep, number 4 indicates no effect on sleep, and numbers 5, 6, and 7 indicate degrees of distuption of sleep.

Beneficial to sleep

$12 \quad 3$

very moderately mildly
No effect

4

What effect do each of these behaviors have upon sleep?

1. Daytime napping

2. Going to bed hungry

3. Going to bed thirsty

4. Smoking more than one pack of cigarettes a day

5. Using sleep medication regularly (prescription or over-the-counter)

6. Exercising strenuously within 2 hours of bedtime

7. Sleeping approximately the same length of time each night

8. Setting aside time to relax before bedtime

9. Consuming food, beverages, or medications containing caffeine

10. Exercising in the early afternoon or early evening

11. Waking up at the same time each day

12. Going to bed at the same time each day

13. Drinking 3 ounces of alcohol in the evening (e.g., 3 mixed drinks, 3 beers, 3 glasses of wine) 


\section{Appendix G (cont'd)}

For each item on the following list, indicate whether you believe it contains caffeine or another stimulant by placing a $\mathrm{Y}$ (yes) or an $\mathrm{N}$ (no) in the space provided. If you are not sure, make your best guess. If you have never heard of an item please place an $\mathrm{X}$ in the space.

7-Up soft drink

regular tea

Dristan cold remedy aspirin

Dr. Pepper soft drink

Midol menstrual relief

lemonade

Dexatrim diet pills

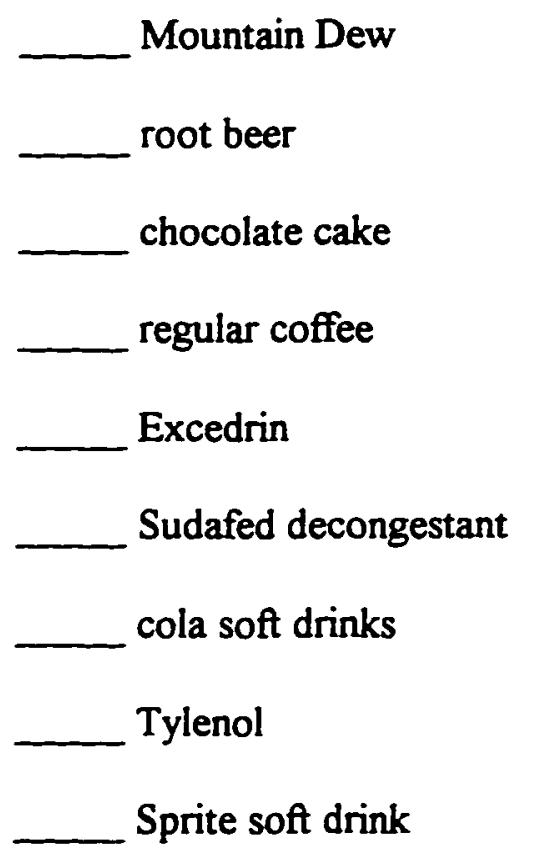

Aqua Ban diuretic
Sprite soft drink

For each of the following behaviors state the number of days per week (0-7) that you engage in that activity or have that experience. Base your answers on what you would consider an average week for yourself.

Indicate the number of days or nights in an average week you:

1. Take a nap

2. Go to bed hungry

3. Go to bed thirsty

4. Smoke more than one pack of cigarettes

5. Use sleeping medications (prescription or over-the-counter)

6. Drink beverages containing caffeine (e.g., coffee, tea, colas) within 2 hours of bedtime 
Appendix G (cont'd)

7. Drink more than 3 ounces of alcohol (e.g., 3 mixed drinks, 3 beers, or 3 glasses of wine) within 2 hours of bedtime

8. Take medications/drugs with caffeine within 4 hours of bedtime

9. Worry as you prepare for bed about your ability to sleep

10. Worry during the day about your ability to sleep at night

11. Use alcohol to facilitate sleep

12. Exercise strenuously within 2 hours of bedtime

13. Have your sleep disturbed by light

14. Have your sleep disturbed by noise

15. Have your sleep disturbed by your bedpartner (put NA if no partner)

16. Sleep approximately the same length of time each night

17. Set aside time to relax before bedtime

18. Exercise in the afternoon or early evening

19. Have a comfortable nighttime temperature in your bed/bedroom

20. Referring to the following definitions provided on dream types, identify the frequency with which your dreams resemble each of the following:

Scale: A. Always (or almost always)

B. Frequently

C. Occasionally

D. Seldom

E. Never (or almost never)

LUCD DREAMS (vivid dreams in which you realize that you are dreaming while you are still in the dream).

ARCHETYPAL DREAMS (dreams that carry a sense of awe and fascination and/or include encounters with strange and unusual beings - perhaps reminiscent of mythology and fairy tales). 
Appendix G (cont'd)

FANTASTIC NIGHTMARES (very vivid, upsetting dreams that you remember in detail upon awakening and can involve a wide range of negative emotions).

PRELUCID DREAMS (where one questions whether one is dreaming, but cannot decide).

CONTROL DREAMS (Where control not possible in waking life is deliberately exercised in the dream, with or without lucid awareness of dreaming).

POST TRAUMATIC NIGHTMARES (dreams repeating an actual past trauma).

NIGHT TERRORS (terrifying awakenings without any recall of dream content). 
Appendix $\mathrm{H}$

Agreement to Participate in Research

San Jose State University

RESPONSIBLE INVESTIGATOR

TITLE OF PROTOCOL:
Kristy Lucero-Gorman

Sleep Hygiene Practices and Knowledge in Different Ethnic Populations of College Students.

I have been asked to participate in a research study that is investigating the sleep habits, sleep problems, and the sleep related knowledge of young adults of different gender and ethnic backgrounds.

I understand that:

1. I will be asked to fill out a questionnaire.

2. I willingly give my consent for the use by the investigator of any pertinent information available on my questionnaire for the purpose of the study.

3. No anticipated risks to myself are expected as a result of participation in the study.

4. The possible benefits of this study to me are an increased awareness about better sleep habits and knowledge about sleep.

5. The most advantageous and efficient procedure is being employed by the author for the study.

6. The results for the study may be published, but any information from this study that can be identified with me will remain confidential and will be disclosed only with my permission.

7. Any questions about my participation in this will be answered by Kristy LuceroGorman (investigator) @ (408) 534-1336. Complaints about the procedures may be presented to Dr. Robert Hicks (graduate student advisor) @ (408) 924-5659; or to Dr. Ken Nishita (Psychology Department Chair) @ (408) 924-5600. For questions or complaints about research subject's rights, or in the event of research-related injury, contact Serena Stanford, Ph.D. (Associate Academic Vice President for Graduate Studies \& Research)@ (408) 924-2480. 


\section{Appendix $\mathrm{H}$ (cont'd)}

8. My consent is given voluntarily without being coerced; I may refuse to participate in this study or in any part of this study, and I may withdraw at any time, without prejudice to my relations with San Jose State University.

9. I have received a copy of this consent form for my file.

I HAVE MADE A DECISION WHETHER OR NOT TO PARTICIPATE. MY SIGNATURE INDICATES THAT I HAVE READ THE INFORMATION PROVIDED ABOVE AND THAT I HAVE DECIDED TO PARTICIPATE.

\section{$\overline{\text { DATE }}$}

SUBJECT'S SIGNATURE

INVESTIGATOR'S SIGNATURE 